\title{
What Do Meditators Do When They Meditate? \\ Proposing a Novel Basis for Future Meditation Research
}

\author{
Karin Matko ${ }^{1}$, Ulrich Ott ${ }^{2}$, and Peter Sedlmeier ${ }^{1}$ \\ ${ }^{1}$ Chemnitz University of Technology \\ ${ }^{2}$ Bender Institute of Neuroimaging, Justus Liebig University Giessen
}

\begin{abstract}
Author note
Karin Matko (D) https://orcid.org/0000-0002-2410-4774

Peter Sedlmeier (iD) https://orcid.org/0000-0002-7998-6313

We have no known conflict of interest to disclose. Data will be made openly available at the Open Science Framework (https://osf.io/bry5u/).

Correspondence concerning this article should be addressed to Karin Matko, Department of Psychology, Chemnitz University of Technology, 09107 Chemnitz, Germany, Email: karin.matko@psychologie.tu-chemnitz.de
\end{abstract}

Contributions: KM designed and executed the studies, analyzed the data, and wrote the first draft of the manuscript. UO collaborated on the study design and data analysis. PS conceptualized the studies and supervised the data analyses. All authors worked on the final version of the manuscript.

Acknowledgments: We thank Michael Tremmel and Ritesh Mariadas for the fruitful discussions regarding the deduction of basic meditation techniques. We also thank Anita Todd, Gesa Kappen, and Vanessa Potter for their helpful comments on a previous version of this manuscript. 


\begin{abstract}
Meditation is an umbrella term for a vast range of contemplative practices. Former proposals have struggled to do justice to this diversity. To our knowledge, there is to date no comprehensive overview of meditation techniques spanning all major traditions. The present studies aimed at filling this gap. In a qualitative study, we compiled a collection of 309 meditation techniques through a literature search and interviews with 20 expert meditators. Then, we reduced this collection to 50 basic meditation techniques. In a second, quantitative study, 635 experienced meditators from a wide range of meditative backgrounds indicated how much experience they had with each of these 50 meditation techniques. Meditators' responses indicated that our choice of techniques had been adequate and two techniques had to be added. Our additional statistical and cluster analyses illustrated preferences for specific techniques across and within diverse traditions as well as sets of techniques commonly practiced together. Bodycentered techniques stood out in being of exceptional importance to all meditators. In conclusion, we found an amazing variety of meditation techniques, which considerably surpasses previous collections. Our selection of basic meditation techniques might be of value for future scientific investigations and we encourage researchers to rely on this set.
\end{abstract}

Keywords: meditation techniques, diversity, preferences, qualitative, cluster analysis 


\section{Introduction}

Meditation has become one of the most popular and widely researched mental training techniques, and meditation and mindfulness are often treated as panaceas for almost anything (Van Dam et al., 2018). However, with its increasing popularity it has become clear that, in fact, "meditation" is not one specific technique but an umbrella term that encompasses a great variety of different techniques (Awasthi, 2013; Dorjee, 2016). These techniques range from the wellknown observance of the breath to the far less common humming meditation or contemplation on death and mortality. This diversity makes it difficult to define meditation and do justice to the vast range of practices associated with it (Bond et al., 2009; Schmidt, 2014). Thus, researchers and practitioners alike would benefit from a comprehensive overview of meditation techniques that would give them insight into what meditators actually do when they are meditating. This was the aim of the present studies. We employed a bottom-up methodological approach and drew on the expertise of experienced meditators from diverse traditions. As a result, we are able to present the first comprehensive compilation of basic meditation techniques, depicting the complexity and diversity of meditation practices found in various meditative traditions and schools. Furthermore, our analysis should provide valuable insight into which meditation techniques are the most popular across and within different traditions and which are commonly practiced together.

Herbert Benson was one of the first researchers to describe the effects of meditation (1975). He investigated the effects of Transcendental Meditation (whose main technique is a form of mantra meditation) and concluded the main effect of meditation was the "relaxation response" it elicited. As the field of meditation research grew, it became clear that this view was shortsighted, as there were other meditation techniques that did not elicit relaxation in practitioners (Amihai \& Kozhevnikov, 2014; Lumma et al., 2015; Peng et al., 2004). An initial and now widespread differentiation distinguished "focused attention" and "open monitoring" as two styles of meditation (Lutz et al., 2008). This differentiation was opened up and extended to include more styles, such as loving-kindness and compassion meditation, which were considered mixtures of focused attention and open monitoring (Lippelt et al., 2014). As research grew, it became clear 
that reducing meditation to these few styles represented an oversimplification of its inherent diversity. Consequently, new collections and classification systems encompassing a greater variety of meditation techniques have been proposed (Brandmeyer et al., 2019; Dahl et al., 2015; Fox et al., 2016; Lutz et al., 2015; Nash \& Newberg, 2013). Nonetheless, these collections and classification systems have still been derived mostly from the top down and they omit several important meditation techniques, especially from the Hindu context (Matko \& Sedlmeier, 2019).

A growing body of research has acknowledged the need to differentiate between different styles of meditation. Meta-analyses have found differential effects for several types of meditation in clinical (Goyal et al., 2014) as well as healthy (Fox et al., 2016; Rose et al., 2020; Sedlmeier et al., 2012, 2018) populations. Comparative studies have begun to distinguish and compare the effects of mantra meditation, breathing meditation, body scan, open monitoring, or observingthoughts meditation, loving-kindness meditation, and compassion meditation. Obviously, these studies did not compare all but rather selections of the abovementioned techniques. In doing so, they found differences in, for example, attention (Lee et al., 2012), affect (May et al., 2014), concentration and emotion regulation (Kropp \& Sedlmeier, 2019), creativity (Colzato et al., 2012), decentering (Feldman et al., 2010), mindfulness (Cebolla et al., 2017), heart-rate variability and perceived effort (Lumma et al., 2015), personal preference (Burke, 2012; R. Tang \& Braver, 2020), phenomenological experience (Przyrembel \& Singer, 2018), and brain activation and deactivation patterns (Fox et al., 2016).

Yet, despite these attempts to acknowledge and do justice to the diversity of meditation techniques, the selection of meditation techniques to be included in a collection has still been limited to the few abovementioned, well-known styles of meditation. Additionally, the selection of techniques has often been arbitrary rather than guided by a sound theory or classification system. To date, only a few studies have investigated the effects of meditation techniques that are less well known but still very important and prevalent in their specific traditions. These techniques include visualization (Amihai \& Kozhevnikov, 2014; Lou et al., 1999), nondual awareness (Josipovic, 2010), supine/relaxation meditation (Gul \& Jahangir, 2019; Kjaer et al., 
2002), chanting (Harne et al., 2019; Wolf \& Abell, 2003), analytical meditation (van Vugt et al., 2020), contemplation (Bach \& Guse, 2015), energy meditation (Venkatesh et al., 1997), dynamic meditation (Bansal et al., 2016), Qigong (Pölönen et al., 2019), or whirling meditation (Cakmak et al., 2017).

As can easily be seen from this rather arbitrary collection, these techniques partly originate from cultural, spiritual, or religious contexts other than the nowadays most prevalent forms of mindfulness meditation. Visualizations are commonly used in the context of Hindu or (Tibetan) Buddhist meditation. Chanting as a form of meditation can be found in Hindu, Buddhist, and Sufi traditions. Energy meditation is commonly practiced by Hindu, Tantric, and Qigong meditators. To date, these various techniques have received a lot less attention in research than the omnipresent mindfulness meditation or the formerly quite popular Transcendental Meditation.

However, one problem that arises with growing diversity in the field is finding a definition that reconciles all these different forms of meditation. Definitions of meditation that have been brought up so far are almost as diverse as the techniques described above. Some authors have emphasized the relevance of particular aspects such as mental training, self-regulation, and attention (Lutz et al., 2008; Tang et al., 2015; Walsh \& Shapiro, 2006; West, 2016), while others have differentiated between meditative states and techniques (Bond et al., 2009; Deshmukh, 2006; Nash \& Newberg, 2013). The purpose of meditation also differs across definitions. According to some definitions, meditation can be practiced for either general well-being, alteration of consciousness, or spiritual insight. These diverse definitions have been discussed in detail elsewhere (Bond et al., 2009; Matko \& Sedlmeier, 2019; Schmidt, 2014). They represent the lack of consensus among experts on when or when not to label a practice meditation. Some authors have argued that finding an overarching definition of meditation might be close to impossible (Ospina et al., 2007; Schmidt, 2014). Others, in turn, have suggested that there might be commonalities across all techniques such as a common goal of reaching a "natural meditative 
state" (Reddy \& Roy, 2019), or that all meditation techniques share a somatic, embodied component (Matko \& Sedlmeier, 2019).

To better identify and comprehend the defining features and working mechanisms of meditation, it is imperative to open up meditation research and investigate meditation in its many forms (Dahl et al., 2015; Ospina et al., 2007; Travis \& Shear, 2010). This might also be helpful in developing one or several overarching theories of meditation (Dorjee, 2016; Sedlmeier et al., 2016). To achieve this, first we need to obtain a good overview of the meditation techniques, which exist throughout different spiritual and cultural contexts and traditions. Although some researchers have pointed out and described a great variety of meditation techniques (Dahl et al., 2015; Ospina et al., 2007; Travis \& Shear, 2010), as of this writing we know of no compilation that is truly comprehensive.

Additionally, in the past, many techniques were labeled with a couple of words, for instance, breathing meditation, without being given concise descriptions of what meditators were actually doing while meditating. However, "breathing meditation" can imply completely different techniques depending on the context. Some meditators count their breaths, some observe their abdomen while breathing, and still others combine breathing with visualizations of light and smoke. It is, thus, essential to describe the specific techniques that meditators are using during meditation in detail. In response to this issue, some researchers have developed taxonomies and frameworks to help researchers and practitioners describe what they are doing during meditation (Allbritton \& Heeter, 2018; Lutz et al., 2015; Nash \& Newberg, 2013; Schmidt, 2014).

Another issue repeatedly raised in the literature is the need to investigate basic meditation techniques that do not include confounding factors, such as supportive exercises or a religious context, to draw accurate causal inferences (Chiesa \& Malinowski, 2011; Isbel \& Summers, 2017). Research has shown that practicing meditation in the specific framework of a belief system can tremendously influence the outcomes of meditation (Amihai \& Kozhevnikov, 2014; Bayot et al., 2020; Hunt et al., 2018). Yet, little is known about the differential effects of basic 
meditation techniques, let alone their interaction with context factors or the effects of combined techniques.

We decided to approach the abovementioned issues from a different perspective, using qualitative and quantitative methods. Instead of deducing meditation techniques from the top down from a researcher's perspective, we chose a bottom-up process of generating basic meditation techniques by involving meditation experts. A similar methodology has already been successfully employed in a study deducing a working definition of meditation (Bond et al., 2009). We approached meditation experts from various traditions with a simple but germane question: "When you meditate, what exactly do you do?" This was the central question guiding our research. Moreover, we decided to break down meditation techniques into their components, or, in other words, the basic techniques. This would make them easily accessible and understandable to many practitioners of diverse backgrounds and, thus, to researchers interested in the basic working mechanisms of meditation.

In our first study, we deduced a set of basic meditation techniques that was as complete as possible, and then in a second study, we evaluated this set in a large sample of experienced meditators. Drawing on these data, we explored the question "What do meditators do when they meditate?" from three different perspectives. First, we approached the question in the most general way by identifying the most popular meditation techniques practiced by a large variety of meditators. Second, we looked at different meditative traditions to see which of these basic techniques are most commonly practiced in each tradition. And third, we focused on the question of which meditation techniques were commonly practiced together by meditators, irrespective of their tradition.

\section{Study 1}

One aim of this qualitative study was to capture as many meditation techniques as possible through a bottom-up empirical investigation. By asking expert meditators in the field and with a thorough investigation of the meditation literature, we looked for a practice-based, 
straightforward answer to our main question: “What do meditators do when they meditate?" We expected to find a large number of different answers in our primary collection of techniques. Therefore, a second aim of this study was to reduce this primary collection to a manageable number of basic meditation techniques.

\section{Method}

To obtain an exhaustive list of meditation techniques, we chose a combination of two approaches. On the one hand, we interviewed an extensive sample of expert meditators representing a wide range of different meditative traditions and schools in Germany. On the other hand, we conducted an extensive literature search. The literature search included meditation manuals from different traditions (Adyashanti, 2006; Anālayo, 2003; Austin, 1998; Bäumer, 2008; Bodian, 2016; Chinmoy, 2013; Kornfield, 2009; Mahasi, 1970; Main, 2013; Nandamalabhivamsa, 2013; Osho, 1983; Ott, 2010; Rinpoche Dagsay Tulku, 2002; Saradananda, 2011; Schimmel, 1992; Shear, 2006; Sivananda, 1975) as well as research papers that included detailed descriptions of meditation practices (Amihai \& Kozhevnikov, 2014; Cebolla et al., 2017; Dahl et al., 2015; Fox et al., 2016; Ospina et al., 2007; Peng et al., 2004; Shannahoff-Khalsa, 2004).

The interviews took place in meditation and yoga centers in Dresden and Bad-Meinberg, Germany, or via telephone. The first author interviewed altogether 20 expert meditators from the following traditions: Different schools of Tibetan Buddhism (Kadampa, Kagyu, and Nyingma), Theravada Buddhism, Zen Buddhism, Yoga, Hinduism, Tantra, Sri Chinmoy, Kundalini Yoga, Osho meditation, Christian meditation, Sufi meditation, Brahma Kumaris, and Qigong.

The semistructured interviews focused on one central question: "When you meditate, what exactly do you do?" This question was asked in an open manner to elicit a free response. The interviewer guided interviewees with repeated inquiries and questions to obtain the most detailed description of the meditation technique they employed during their meditation sessions. This was repeated for all practices mentioned. Then, the interviewer asked whether there were any more techniques that the interviewees used less often and, in the case of the interviewee being a meditation teacher, whether there were any more techniques that they taught to their students. 


\section{Results}

This exhaustive search resulted in a list of overall 309 meditation practices (see Supplementary Material A). Since many techniques were combinations of diverse techniques, we segmented our list into primary and secondary techniques. The primary technique represented the main practice, whereas the secondary technique(s) represented optional auxiliary or combinable practices, or variations of the main practice. Approximately two thirds of these techniques were reported during the interviews, and one third originated from literature and manuals.

This extensive list was reduced in several steps. First, we removed all duplicates of identical techniques, for example, identical forms of observing the breath. Second, all techniques were sorted into 14 intuitive categories by the first author to get a general overview. These categories were (1) breath, (2) observing thoughts, contemplation, insight, (3) prayer, opening up, grace, mysticism, (4) visualizations, (5) repeating a mantra or an affirmation, (6) observing the body, (7) sensing/feeling of energy, emotions, or affect-centered objects, (8) open monitoring or doing nothing in particular, (9) experiencing nonduality or emptiness, (10) chanting, singing, humming, music, (11) concentrating on an object, (12) moving the body, (13) cultivating virtues, positive attributes, or good wishes, and (14) informal practice. After all remaining techniques had been sorted into these categories, more duplicates were removed in dialogue with all authors, resulting in 171 meditation practices (list available on request).

Because we considered 171 techniques to be still too many to be used in the second study, the third step focused on the deduction of a manageable number of representative basic meditation techniques. All practices were reread carefully and their basic techniques were extracted following the these rules:

- Technical terms were replaced by more commonly used words, for example, "chakra" was replaced by "energy center." 
- The level of abstraction was increased for practices that were too specific, for example, "visualizing a rose blossom in the heart" and "visualizing an expanding light in the heart" were subsumed under "visualizations associated with the opening of the heart."

- Very similar practices were subsumed to superordinate techniques, for example, "sitting upright and allowing the body to circle around one's own axis," and "standing upright with the eyes closed and allowing the body to move smoothly without intervening" were subsumed under "sitting or standing upright with the eyes closed and allowing the body to move smoothly without intervening."

- Techniques that involved direct manipulation of breath, for example, rapid breathing or decelerating the breath, were subsumed under one category, as in some traditions they are considered preparatory rather than meditation practices.

After extensive discussions among the authors, it was decided to remove techniques that were too vague in their description to be understood by people not familiar with this specific practice, for example, "letting go of all suppressed emotions ('catharsis')" or "resting on primordial awareness/consciousness, in state of profound stillness and silence." Furthermore, it was agreed to exclude meditation or mindfulness as a practice of daily life ("informal practice"), as it was not considered a "formal" meditation technique comparable to the other basic techniques. This reduction led to a list of 50 basic meditation techniques, depicted in Table 1. 


\section{Table 1}

The 50 Basic Meditation Techniques and Their Abbreviations Utilized in the Present Paper

$\begin{array}{ll}\text { Basic meditation technique } & \text { Abbreviation }\end{array}$

(1) Accumulating energy in specific centers (e.g., abdomen) and Channel_Energy

channeling it through certain pathways (e.g., spine)

(2) Being mindful of the respiratory flow in the entire body Resp_Flow

(3) Being mindful of the rise and fall of the abdomen while Abdomen_Breath breathing

(4) Being mindful of the sensations arising in the nose during Nose_Breath inhalation and exhalation

(5) Carrying out predetermined, meditative sequences of

Meditative_Movement movements while allowing the breath to flow naturally

(6) Combining inhalation and exhalation with visualization of Breath_Visualization energy, qualities, light, smoke, etc.

(7) Concentrating on a location in the body (e.g., abdomen or an Concentrate_Energy "energy center" like chakra, Dan Tien) or on a series of locations in the body/"energy centers"

(8) Concentrating the mind on something contradictory without

Contradiction thinking about the contradiction

(9) Contemplating a spiritually important question (e.g., "Who Contemplate_Question am I?")

(10) Contemplating death and one's own mortality Contemplate_Death

(11) Contemplating the conditional emergence of experiences Contemplate_Condition (cause \& effect) 
Basic meditation technique

Abbreviation

(12) Counting breaths

Count_Breath

(13) Creating a visual representation of a deity and then

Deity_Merging

merging with this visualization

(14) Cultivating compassion, sympathetic joy, equanimity,

Compassion

loving kindness (for oneself, friends, neutral people, enemies,

the whole world)

(15) Droning or humming continuously with optional

Humming

corresponding hand movements

(16) Fixating on an object without blinking/"staring" (candle

Fixate_Object

flame, picture, hand)

(17) Focusing on internal sounds and vibrations

Internal_Sounds

(18) Focusing on one point of the body and letting the breath

Point_Breath

flow through this point of concentration

(19) Focusing on the pauses between inhalation and exhalation, Pause_Breath carefully observing what happens

(20) Fostering and focusing on a spiritual connection created by Singing_Together singing together

(21) Labeling mental experiences with words that describe

Labeling

these experiences

(22) Listening to the sound of singing bowls or a gong and

Listen_Sounds

feeling the corresponding vibrations inside the body

(23) Looking at/focusing on a sacred object (image of the

Focus_Object master, sacred geometric pattern, etc.) 
Basic meditation technique

Abbreviation

(24) Lying down and going into a state of deep relaxation while Lying_Relaxing being fully conscious

(25) Mentally repeating syllables or words while connecting Repeat_Words_Breath them to the rhythm of breathing

(26) Observing emotions without adhering to them

Observe_Emotions

(27) Observing how bodily sensations arise without adhering to

Observe_Body them

(28) Observing how thoughts arise in the mind without Observe_Thoughts adhering to them

(29) Opening oneself up to blessings and inspiration

Opening_Up

(30) Perceiving, then releasing emotions and tensions (e.g., with Release_Tensions the help of the breath), while scanning the body

(31) Reading certain paragraphs of a text over and over again Read_Text and taking them in

(32) Reciting a mantra loudly, in a whisper, and silently

Recite_Mantra

(33) Repeating a mantra using a mnemonic (e.g., prayer beads)

Mantra_Mnemonic

(34) Repeating a mantra while focusing on corresponding

Mantra_Bodypoints points in the body

(35) Repeating an affirmation (e.g., "I am patient")

Repeat_Affirmation

(36) Scanning the entire body

Scan_Body

(37) Singing sutras/mantras

Singing_Sutras_Mantras 
Basic meditation technique

Abbreviation

(38) Sitting and gazing at the wall, observing oneself doing

Sitting_Do_Nothing

nothing

(39) Sitting or standing upright with the eyes closed and

Move_Smoothly

allowing the body to move smoothly without intervening

(40) Spinning around one's own axis with the arms spread out

Spinning

(41) Trying to feel one's heartbeat

Feel_Heartbeat

(42) Visualizations associated with light or fire at different body

Visualize_Light_Fire

parts

(43) Visualizations associated with the opening of the heart

Visualize_Heart_Opening

(e.g., rose blossom)

(44) Visualizing how the dead human body slowly decays and

Visualize_Decay

decomposes

(45) Visualizing that thoughts are inherently restless and

Visualize_Thoughts_Silence

focusing on the silence and the vastness that lies beyond them

(46) Visualizing the body expanding in all directions

Visualize_Expanding

(47) Voluntary manipulation of breath, e.g., reducing the

Manipulate_Breath

strength of breathing or "pranayama" with holding one's breath

(48) Walking and being mindful of sensory perceptions

Walking_Senses

(movement of the feet, legs, clothing, air, hair etc.), coordinating

it with the breath if necessary

(49) Walking, dividing the walking process into parts, and

Walking_Labeling internally labeling each partial movement 


\author{
Basic meditation technique \\ Abbreviation \\ (50) With a specific intention (e.g., open one's heart, raise one's Intention_Mantra \\ mood) selecting and repeating a mantra, combining it with \\ associated hand postures or arm movements
}

Note. Techniques are arranged in alphabetical order.

\title{
Discussion
}

In this qualitative study, we gathered all accessible meditation practices from 15 diverse traditions and reduced them to 50 basic meditation techniques. Although we have taken pains to arrive at a comprehensive collection of meditation techniques, we do not claim to have gathered all existing techniques as, for example, some techniques are kept secret to people belonging to a specific tradition (e.g., Tantric Buddhism), and some minor schools might have been overlooked by our research team. To our knowledge, this list of 50 basic meditation techniques surpasses all former attempts to depict the diversity of meditation techniques in a clear-cut way. It also includes far less prominent techniques that have rarely been researched, so far.

At the same time, we aimed at simplifying the complex nature of meditation by extracting basic meditation techniques underlying the many combined practices we found in our analysis. In many traditions, meditation is practiced in sets of different techniques that can sometimes be as simple as counting the breath but can also involve complex and progressing stages of visualization or breath work (Amihai \& Kozhevnikov, 2014; Austin, 1998; Osho, 1983; Peng et al., 2004). We tried to disentangle these complex practices as far as possible, on the one hand to make them more accessible and on the other to ease scientific investigation into the "active ingredients" of meditation. Yet, it remains largely unclear to what extent the effects of meditation interventions can be attributed to specific techniques, teachers, settings, traditions, personality traits, or specific combinations or sequences of techniques. Our list of 50 basic meditation techniques could provide a means to scientifically addressing some of these issues. 
Nonetheless, the question of whether our selection of meditation techniques would generalize to a broader audience of experienced meditators remained unanswered. For this reason, we decided to conduct an extensive online survey, reaching out to a broad range of experienced meditators with all kinds of meditative backgrounds. This would allow us to validate our qualitative results using quantitative methodology.

\section{Study 2}

This study addressed the question "What do meditators do when they meditate?" in a broader sense. We wanted to see whether experienced meditators from all kinds of different contemplative traditions would be able to identify their personal practice in our selection of meditation techniques and/or whether they would add techniques that we might have overlooked. In other words, we were interested in whether our selection of techniques had been adequate. At the same time, by obtaining their traditional background and the amount of experience they had with each technique, we were able to draw conclusions from their ratings on the popularity and prevalence of each technique, generally and tradition-wise. With this, we were able to answer the above question from three different perspectives: What do meditators do when they meditate in general? What do they do in their specific tradition? What do they do with respect to combining several techniques?

\section{Method}

\section{Procedure}

To answer these questions, we devised a four-part online survey using the SoSci Survey platform (Leiner, 2019). First, meditators were asked to answer questions regarding their meditation experience and their current or past meditation practice/routine. Second, they were asked to name all traditions the meditation techniques they practiced were derived from, in reverse chronological order, that is, the most recent first. Third, they were given the list of 50 basic meditation techniques and asked to rate how much experience they had with each of the 50 techniques on a 6-point Likert scale (from $1=$ no experience at all to $6=a$ lot of experience). If an 
important technique they were practicing was missing, they had the opportunity to add up to two techniques to the list and rate their experience with these. Last, they answered a few sociodemographic questions.

We used snowball sampling to reach as many experienced meditators from as many traditions as possible. The internet was searched extensively for schools, centers, societies, and associations of meditation, yoga, or contemplation in Germany, Austria, and Switzerland. We identified around 100 contacts in this way. Then, we sent the online survey to these contacts with the request to spread the survey and forward it to as many meditators as possible. Most meditation centers and societies agreed to do so.

\section{Participants}

The survey addressed "experts in meditation" from any spiritual or meditative tradition or background with any level of meditation experience. Altogether 878 experienced meditators responded to the survey, and 661 completed the survey. We excluded all participants who did not provide any data on their lifetime experience with meditation and/or on the tradition in which they were practicing. Two participants had to be excluded because they rated having the same amount of experience with all meditation techniques, which we deemed very unlikely. The final sample was composed of 635 participants, $60.9 \%$ women. The mean age was 52.32 years $(S D=$ 10.71; range 21-92 years). At the time of the survey, $92.3 \%$ of the participants were living in Germany.

Participants had practiced meditation for 6 months up to 57 years $(M=15.01$ years, $S D=$ 11.11). On average, they reported practicing meditation 6.03 times a week $(S D=3.61)$ for 31.35 min per session $(S D=22.89)$. The majority of participants reported having taught meditation occasionally $(40.8 \%)$ or regularly $(23.0 \%)$ and described their meditation practice as very (30.4\%) or fairly (42.4\%) regular. Participants reported affiliations with a great variety of meditative traditions and schools, which we subsumed under 19 categories of major meditative traditions (see below). 
Of all participants, $48.7 \%$ reported holding a university degree, $19.5 \%$ had graduated from high school, $6.8 \%$ had completed their doctorate, and $12.8 \%$ had acquired a professional qualification. Regarding employment, $32.9 \%$ of participants were working as employees, $37.0 \%$ were self-employed, and $8.5 \%$ were retired.

\section{Results}

We performed multiple analyses to provide a multifaceted response to each question. One set of analyses was based on all 50 meditation techniques to obtain a complete picture of the adequateness of our selection and the distribution and clustering of the techniques. A second set of analyses focused on the top 10 preferred techniques of all participants or of subsets of participants. This was done in an attempt to simplify and reduce the vast number of techniques under investigation. The two types of analyses complement each other in supplying an in-depth examination of what meditators do when they are meditating.

Data were analyzed quantitatively by employing descriptive, correlational, and cluster analyses. All statistical analyses were performed using R 4.0.2 (R Core Team, 2020). Bar charts were generated with the statistical package ggplot2 (Wickham, 2016), and dendrograms with the package ggdendro (de Vries \& Ripley, 2020). Results on all three research questions will be reported consecutively in the following.

\section{What Do Meditators Do When They Meditate: The Commonalities}

Do experienced meditators agree with our selection of basic meditation techniques? Which meditation techniques are especially popular among meditators of all traditions? We relied on the two analytic approaches described above to answer these two questions. The first question was analyzed encompassing all 50 techniques, whereas the second question aimed at simplifying our selection by extracting the top 10 preferred techniques of all meditators.

We descriptively evaluated the ratings of all participants on all meditation techniques. If our list of techniques included insignificant ones, we would anticipate that none of the experienced meditators would have a lot of experience with this specific technique. If we had 
omitted important techniques, we would expect them to consistently appear in the further added techniques. At the same time, these added techniques should not be variations of our already present 50 basic techniques. To deduce the most popular techniques, we calculated mean experience scores across all participants for each meditation technique and built a ranking sequence based on these scores.

\section{Adequateness of 50 Meditation Techniques}

In general, all 50 meditation techniques were commonly used. Every technique received all possible rating scores, ranging from the minimum of 1 (no experience at all) to the maximum of 6 (a lot of experience). On average, each technique had around 129 experienced meditators $(20.4 \%$ of the sample; $S D=10.5 \%)$ who reported having a lot of experience with that particular technique. The most popular technique in this regard, that is, the one with the highest rating score (scanning the body), had 277 meditators, while the least popular technique (visualizing decay) still had 13 meditators reporting having a lot of experience with it. At the same time, each technique had an average of 147 participants $(23.2 \%$ of the sample; $S D=14.5 \%)$ who had no experience practicing it. The techniques with the highest (419) and lowest (23) number of participants with no practice experience were the same as above-visualizing decay and scanning the body, respectively.

This means that for every meditation technique, there were at least 23 experienced meditators who never used it and at least 13 who used it a lot, which speaks to our selection of practices. A more detailed exposition on how rating scores were distributed across all meditation techniques can be found in the Supplementary Material (Table B1).

Next, we looked at the average number of meditation techniques our participants were acquainted with. On average, experienced meditators from our sample reported having no experience at all with $11.6(S D=9.7)$ techniques, a little experience with $7.7(S D=5.2)$, some experience with $6.4(S D=4.3)$, more experience with $6.9(S D=4.2)$, quite a lot of experience with $7.3(S D=5.8)$, and a lot of experience with $10.2(S D=9.4)$ meditation techniques. Consequently, participants reported already having practiced 38 of the 50 meditation techniques, at least to 
some extent. This further validates our list of techniques as they, indeed, seem to be widely practiced.

Of all meditators, $6.6 \%$ reported having employed all techniques at least once in their life. The absolute minority of respondents, $0.008 \%$, reported having used only 10 or fewer meditation techniques over the course of their practice. Thus, it seems that most experienced meditators did have accumulated experience with quite a few different meditation techniques over their lifetime of meditation practice. However, most meditators seemed to have a set of around 10 preferred techniques they most engaged with in their practice. Personal preferences ranged from very popular meditation techniques, such as observing the breath, to less common techniques, such as visualizing how the human body slowly decays and decomposes.

Furthermore, participants had the opportunity to add any meditation technique they felt was missing from the list. Altogether 240 techniques were added (list available on request). Again, we analyzed these techniques descriptively by extracting and grouping similar techniques. The analysis revealed four main groups of techniques:

- Osho (or similar) techniques, for example, "catharsis" ( $n=18)$, which we had considered in our first list of 309 techniques but excluded because they fell under the criterion of being too vague in their description to be understood by people not familiar with this specific practice.

- Sitting in silence $(n=35)$, which we had considered in our first list but excluded as a "vague" practice.

- Koan, Mahavakya, or similar techniques $(n=9)$, which we had included in our list but for which we probably had not chosen the right wording.

- Other techniques $(n=178)$ that

- either fell under one of the exclusion criteria mentioned above, that is, they were either too general (e.g., "Zen", "Yoga"), too specific (e.g., "heart chakra meditation," "tree meditation"), or an informal practice (e.g., "mindfulness as a practice of daily life"); 
○ or were already included in the list (e.g., "mantra meditation," "observing thoughts and emotions").

Subsequently, we made three slight adjustments to our original list (depicted in Table 1). We decided to reword one technique and to extend our list by including two more basic techniques. Specifically, we included "sitting in silence" and "expressive practices," such as catharsis or shaking, which are often employed in the context of Osho meditation. To aid understanding, we reworded Technique 8 ("concentrating the mind on something contradictory without thinking about the contradiction") to "concentrating the mind on something contradictory, a paradox, or a sentence of wisdom without thinking discursively about it (e.g., Koan, Mahavakya)." Thus, our final set included 52 basic meditation techniques. Yet, all of the following analyses are based on the 50 techniques we explicitly had requested participants to rate in this study.

\section{The 10 Most Popular Meditation Techniques}

We calculated the mean score of rated experience with each meditation technique across all participants to build a ranking sequence of preferred techniques. Our underlying assumption was that the meditation techniques that meditators rated as having "a lot of experience" with were being practiced more often in the present or had been practiced quite a lot in the past. Thus, it can be assumed that these techniques were more popular and important in meditators' regular meditation practice than other techniques. Table 2 shows the top 10 meditation techniques that received the highest mean scores across all meditators from all traditions. 


\section{Table 2}

Mean Rating Scores and Standard Deviations of the 10 Most Popular Meditation Techniques Across All Participants (N = 635)

\begin{tabular}{lccc}
\hline Meditation technique & $M$ & $S D$ \\
\hline Scanning the entire body & 4.71 & 1.48 \\
Being mindful of the rise and fall of the abdomen while breathing & 4.68 & 1.50 \\
Observing how thoughts arise in the mind without adhering to them & 4.66 & 1.44 \\
Being mindful of the respiratory flow in the entire body & 4.54 & 1.53 \\
Perceiving, then releasing emotions and tensions (e.g., with the help of the & 4.41 & 1.56 \\
breath), while scanning the body & 4.34 & 1.54 \\
Cultivating compassion, sympathetic joy, equanimity, loving kindness (for & & \\
oneself, friends, neutral people, enemies, the whole world) & 4.28 & 1.59 \\
Observing how bodily sensations arise without adhering to them & 4.21 & 1.76 \\
Singing sutras/mantras & 4.19 & 1.76
\end{tabular}

As can be observed from Table 2, the three most popular meditation techniques across all participants were scanning the body, observing the abdomen while breathing, and observing thoughts. Consistently, these are possibly the three most widely known meditation practices.

In this list of 10 techniques, five others stand out as having a clear body-oriented focus, that is, observing the breath in the nose and in the body, observing bodily sensations, releasing tensions in the body, and supine meditation (lying down and being relaxed but conscious). Therefore, body-centered techniques seem to be of particular importance for meditation. Only observing thoughts, singing sutras/mantras, and cultivating compassion or similar virtues refer 
to techniques not exclusively linked to the body, though they certainly involve some somatic component.

We also had a look at the least popular meditation techniques, that is, techniques that only a few meditators reported having much experience with. The three least popular meditation techniques across all participants were visualizing how the body slowly decays $(M=1.69)$, spinning around one's own axis $(M=1.80)$, and concentrating the mind on something contradictory $(M=2.02)$. Perhaps this is not surprising, as these techniques are considered very advanced and/or specific to certain traditions that might have been underrepresented by our sample of meditators. Whereas the first of these three techniques is commonly practiced by Theravada Buddhist monks and nuns, the second is considered a typical Sufi technique. The third was the technique we chose to reword because some meditators might have misinterpreted its description (see above). Thus, to provide a more differentiated picture of the diversity of practices, we decided to run a few tradition-specific analyses. This led us directly to the second research question.

\section{What Do Meditators Do When They Meditate: The Differences}

After gaining some general insight into the preferred techniques across a diverse sample of meditators, we were interested in how these findings would generalize across preferences in specific meditative traditions. For this reason, we first evaluated which traditions were represented in our sample. Second, we compared preferred techniques in our two largest groups of meditators, that is, Buddhist and Hindu meditators. And third, to obtain an even more accurate picture, we subdivided our sample into 12 major groups of meditative traditions and compared their preferred meditation techniques with one another.

The majority of these analyses were based on an evaluation of the top 10 preferred techniques in each tradition. However, we also estimated the similarity and differences between the 12 traditions more accurately by subjecting their full ranking sequences (including all 50 techniques) to a cluster analysis. 


\section{Meditative Traditions in the Sample}

Participants were provided with a free input field to list all meditative traditions they were affiliated with and to provide the name of any prominent teacher in their school. Then, we closely examined and processed all enumerated traditions in three consecutive steps. First, we extracted and categorized all unique names of traditions and spiritual teachers until the list was complete and no new names could be added. Second, we aggregated these names into larger groups of related traditions and teachers. And third, we generated a final categorization of superordinate traditions by carefully grouping them into as many categories as necessary and as few as possible. This process was guided by three different considerations:

(a) Clustering similar traditions (e.g., Soto and Rinzai Zen into "Zen Buddhism"),

(b) Representing the highest possible diversity in philosophical, cultural, or geographical origin (e.g., Indian, Abrahamic, Chinese),

(c) Retaining distinctive traditions, which were strongly represented in our sample (e.g., Sivananda vs. Kundalini Yoga).

We identified 18 superordinate traditions in this way. In a final step, we allocated participants to these superordinate traditions based on the descriptions they had given in the questionnaire. They could be assigned to several groups of traditions if they had been practicing in different meditative traditions. Table 3 gives the superordinate traditions and the number of participants having practiced in these. 


\section{Table 3}

List of Superordinate Traditions Present in the Sample and Number of Experienced Meditators (n) Practicing or Having Practiced in These Traditions

Superordinate tradition Number of meditators $(n)$

Zen 219

Sivananda Yoga 156

Theravada, Vipassana 144

Other Hindu traditions: 116

Vaishnavism, Sri Chinmoy, Sri Aurobindo, Mother

Meera, Ramana Maharshi, Deepak Chopra,

Transcendental Meditation, and others

Tibetan Buddhism

99

Yoga (other)

84

Kundalini Yoga

Osho meditation 46

Mindfulness-based stress reduction 32

Sufism

Christianity 26

Qigong/Tai Chi 17

No tradition/free meditation

Tantra 


\begin{tabular}{ll}
\hline Superordinate tradition & Number of meditators $(n)$ \\
\hline Anthroposophy & 3 \\
Merkabah/Jewish & 3 \\
Other, e.g., Acem, hypnosis & 24 \\
\hline
\end{tabular}

Several participants reported having practiced in different meditative traditions. Therefore, the total number of allocated traditions $(n=1,107)$ surpasses the total number of participants. On average, participants reported practicing in $1.74(S D=1.04$, range $1-6)$ of these traditions.

The majority of participants had practiced in either Buddhist $(n=462)$ or Hindu $(n=449)$ meditative traditions. However, we were also able to reach less prominent groups of meditators, such as Christian ( $n=26)$, Sufi $(n=29)$, and Qigong/Tai Chi $(n=17)$ meditators.

To derive tradition-specific preferences for meditation techniques, we ran three analyses. First, we divided the sample into purely Buddhist and purely Hindu meditators and calculated their top 10 preferred meditation techniques. Second, we assigned each participant to one of 12 major meditative traditions, based on their most recent tradition. Then, we built ranking sequences for each tradition and compared them with each other by (1) using their top 10 preferred techniques and (2) subjecting their full ranking sequences to a cluster analysis. We present our results in the following.

\section{Hindu Versus Buddhist Meditators}

Participants who reported practicing in one or more Buddhist traditions (i.e., Zen, Theravada, Vipassana, or Tibetan schools) but in no tradition from another spiritual background were allocated to the group of Buddhist meditators $(n=216)$. Participants practicing in one or more Hindu traditions (i.e., Sivananda Yoga, Kundalini Yoga, other Yoga, or in affiliation with Hindu masters such as Osho, Ramana Maharshi, Sri Aurobindo, Mother Meera, or Sri Chinmoy) 
but in no other spiritual tradition formed the group of Hindu meditators $(n=204)$. Participants of any other spiritual or mixed spiritual backgrounds were not included in the following analyses.

Table B2 in the Supplementary Material gives the number and percentage of subgroups of traditions in both groups. Practitioners of Zen Buddhism and Sivananda Yoga were slightly overrepresented in our sample. However, we know of no representative survey giving reliable base rates of meditators practicing in the respective traditions. Still, both abovementioned traditions are very popular in Germany.

As for the previous analysis, we calculated the mean score of each meditation technique for both groups, that is, Hindu and Buddhist meditators, and built ranking sequences. Higher scores indicate more overall experience in practicing the respective technique. To ease comparison between the two groups of meditators, we visually present their top 10 preferred techniques in a comparative bar chart (Figure 1). This figure depicts 17 techniques that appeared in any of the two top-10 lists with their corresponding mean ratings in both groups. It is ordered according to the top-10 list of Buddhist meditators to enhance comparability. Stars and daggers indicate the top 10 preferred techniques for Buddhist and Hindu meditators, respectively. Tables showing the top 10 preferred techniques separately for Buddhist and Hindu meditators can be found in the Supplementary Material (Tables B3 and B4). 


\section{Figure 1}

Comparative Bar Chart Depicting the Top 10 Preferred Meditation Techniques of Buddhist ( $\mathrm{n}=216)$ and Hindu ( $\mathrm{n}=204)$ Meditators and Corresponding Mean Ratings in Both Groups

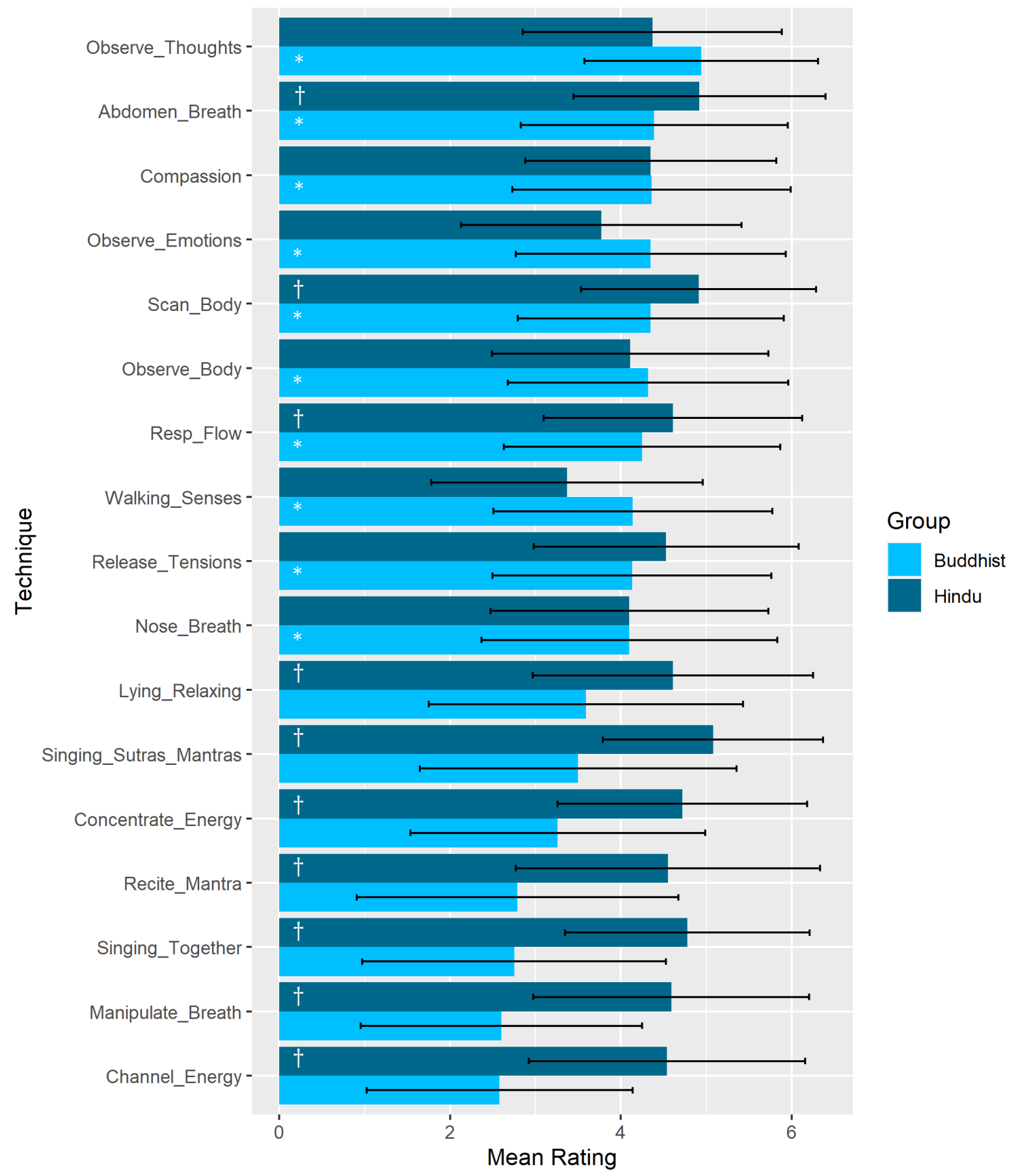

Note. ${ }^{*}=$ Top 10 preferred techniques of Buddhist meditators; $\dagger=$ top 10 preferred techniques of Hindu meditators. Whiskers represent standard deviations. See Table 1 for descriptions of technique codes. 
Looking at the stars and daggers in Figure 1, very clear distinctions in preferred techniques appear between Buddhist and Hindu meditators. Both top-10 lists have only three meditation techniques in common: observing the respiratory flow, observing the abdomen while breathing, and scanning the body. All other techniques differ and reflect tradition-specific preferences for techniques. Buddhist meditators prefer techniques such as observing thoughts or emotions, walking meditation, and cultivating compassion or loving-kindness. Hindu meditators, on the other hand, practice singing or reciting mantras, concentrating on locations in the body or "energy centers," and manipulating the breath. These preferences correspond to both statements of experienced meditators from Study 1 as well as meditation manuals from the respective traditions (Bodian, 2016; Chinmoy, 2013; Kornfield, 2009; Mahasi, 1970; Nandamalabhivamsa, 2013; Saradananda, 2011; Sivananda, 1975). Moreover, it seems that Hindu meditators also practice techniques preferred by Buddhist meditators quite a lot, but not vice versa.

Comparing these results to the overall top 10 , the latter seem like a mixture of preferred meditation techniques from Buddhist and Hindu traditions. All three techniques that overlap in both traditions reappear in the top 10, as well as four more techniques from Buddhist traditions (observing bodily sensations or thoughts, cultivating compassion etc., releasing tensions in the body) and three more techniques from Hindu traditions (singing sutras/mantras, supine meditation, concentrating on a location in the body).

As both groups of meditators, Buddhist and Hindu, represent a substantial proportion of meditators in our sample, $34.0 \%$ and $32.1 \%$, respectively, it might well be that the abovementioned general top-10 list is slightly skewed. Nonetheless, it might also be possible that these techniques represent techniques actually preferred by many meditators independent of their tradition. To check this assumption we prepared ranking sequences for 12 major spiritual traditions. Then, we calculated the proportion of overlap between them and clustered them according to the distances between their ratings. 


\section{Preferred Meditation Techniques in 12 Major Traditions}

To make our results more discernible, we decided to allocate each participant to one single tradition. If meditators reported practicing in more than one tradition, we allocated them to the tradition they described as their current one. If two traditions were mentioned as equally important, a randomized trial (throwing a coin) determined the allocation. Thereafter, we excluded all traditions with fewer than five meditators allocated to them, for example, shaman, anthroposophical, or Jewish meditators. As the "other" category was far too heterogeneous to be interpreted meaningfully, we refrained from including it in our analyses. We also excluded meditators with "no tradition."

As a result, we obtained 12 categories of major meditative traditions. Respective sample sizes, gender ratios, mean ages, and mean meditation experiences of participants in each of the 12 traditions can be found in Table B5 in the Supplementary Material. We are well aware that subgroups with smaller sample sizes (such as the five designated Qigong/Tai Chi meditators in our subsample) provide less reliable estimates than subgroups with larger sample sizes. Therefore, the results should be interpreted with care.

Following the procedure described above, we calculated the mean experience with each meditation technique within each subgroup of meditators and, again, built ranking sequences for each tradition. Then, we performed three analyses to generate a precise picture of differences and commonalities between traditions. First, we extracted the 10 most popular meditation techniques within each tradition and calculated the percentage of overlap in preferred techniques across all traditions. Second, including all 50 techniques, we used hierarchical clustering to determine the proximity/distance between the mean ratings in diverse traditions. And third, we identified distinctive meditation techniques that were uniquely preferred by one specific tradition, relying on their top 10 techniques.

To calculate the percentage of overlap, we divided the number of techniques shared in two traditions by 10 . Resulting percentages are given in Table 4. As only the top 10 ranked meditation techniques were compared to each other, a score of 0.3 , for instance, indicates that 
three of 10 techniques overlapped in two traditions. The mean percentage of overlap between all traditions was $44.4 \%(S D=17 \%)$. Full ranking sequences for all traditions can be found in Supplementary Material C. 


\section{Table 4}

Percentage of Overlap Between Ranking Sequences of the Top 10 Preferred Techniques in 12 Major Meditative Traditions

\begin{tabular}{|c|c|c|c|c|c|c|c|c|c|c|c|c|}
\hline Technique & Zen & Theravada & Tibetan & Sivananda & Kundalini & Yoga & Hindu & Osho & MBSR & Christian & Sufi & $\begin{array}{l}\text { Qigong/ } \\
\text { Tai Chi }\end{array}$ \\
\hline Zen & 1 & & & & & & & & & & & \\
\hline Theravada & 0.7 & 1 & & & & & & & & & & \\
\hline Tibetan & 0.5 & 0.6 & 1 & & & & & & & & & \\
\hline Sivananda Y. & 0.3 & 0.3 & 0.3 & 1 & & & & & & & & \\
\hline Kundalini Y. & 0.1 & 0.1 & 0.2 & 0.6 & 1 & & & & & & & \\
\hline Yoga other & 0.6 & 0.6 & 0.4 & 0.7 & 0.4 & 1 & & & & & & \\
\hline Hindu & 0.2 & 0.3 & 0.4 & 0.6 & 0.5 & 0.3 & 1 & & & & & \\
\hline Osho & 0.7 & 0.7 & 0.6 & 0.6 & 0.4 & 0.7 & 0.4 & 1 & & & & \\
\hline MBSR & 0.7 & 0.8 & 0.5 & 0.4 & 0.2 & 0.7 & 0.3 & 0.7 & 1 & & & \\
\hline Christian & 0.5 & 0.6 & 0.3 & 0.4 & 0.1 & 0.4 & 0.4 & 0.4 & 0.6 & 1 & & \\
\hline Sufi & 0.3 & 0.4 & 0.4 & 0.6 & 0.4 & 0.4 & 0.6 & 0.4 & 0.3 & 0.3 & 1 & \\
\hline Qigong/Tai Chi & 0.6 & 0.5 & 0.4 & 0.3 & 0.2 & 0.5 & 0.3 & 0.5 & 0.5 & 0.3 & 0.3 & 1 \\
\hline
\end{tabular}

Note. Bold type indicates overlap of less than $20 \%$. Bold italic indicates overlap of more than $80 \%$ of techniques. MBSR $=$ Mindfulness-based stress reduction; $\mathrm{Y}=$ Yoga. 
Interestingly, Table 4 indicates that each meditative tradition has at least one prominent overlapping technique with each other tradition. Again, the two most popular techniques in almost all traditions were observing the breath in the abdomen and scanning the body (both found in 11 of the 12 traditions), followed by observing the respiratory flow (8 of 12 traditions). This finding corresponds to prior results presented in this paper, both the general top 10 as well as the top 10 of Buddhist and Hindu meditators. Thus, it seems these techniques are indeed practiced by many meditators irrespective of their current meditative tradition. Furthermore, this highlights the strong importance of body-centered meditation techniques found and taught in many traditions (Ott, 2010; Sedlmeier, 2016).

Remarkably, we found the least overlap between Kundalini Yoga and other traditions. Although some overlap exists with other Yoga or Hindu traditions, the overlap to other traditions' preferred meditation techniques is minimal. A similarly small overlap was observed for techniques of Hindu and Zen meditators. The traditions with the highest overlap are Theravada Buddhism and mindfulness-based stress reduction (MBSR), which might reflect the strong influence of Kabat-Zinn's Theravada practice on the development of MBSR (Kabat-Zinn, 2013).

Next, we used cluster analysis to identify similarity in groups of traditions based on their ratings of all 50 meditation techniques. Cluster analysis maximizes homogeneity within as well as heterogeneity between clusters of objects and is performed with a proximity matrix (Kaufman \& Rousseeuw, 2009). This proximity matrix can resemble either similarities (correlations) or dissimilarities (distances) between objects. We considered the distances between ratings to be more relevant for our research question than their covariation. Therefore, we calculated Euclidean distances between the mean ratings across all 50 techniques of all traditions and submitted them to a Ward's hierarchical agglomerative cluster analysis. The resulting dendrogram is presented in Figure 2. 


\section{Figure 2}

Dendrogram of Relative Distances Between Ratings of 12 Major Meditative Traditions

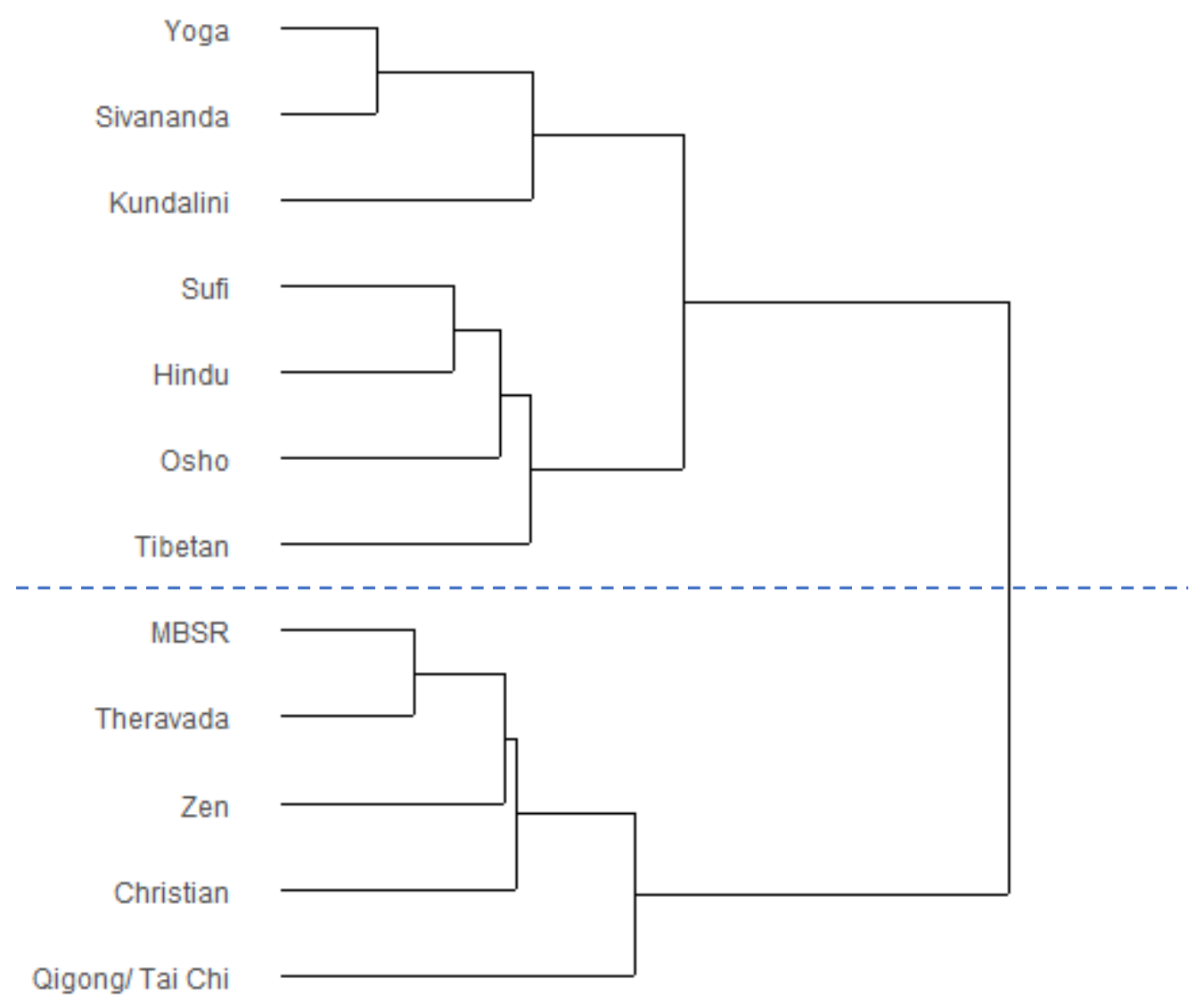

Note. The blue dashed line represents the partitioning of two clusters. MBSR = Mindfulness-based stress reduction.

Dendrograms are analyzed visually by inspecting the relative lengths of their bars. Shorter bars indicate a smaller distance between objects whereas longer bars represent a greater distance. Thus, similar traditions appear closer to each other in the dendrogram in Figure 2. After careful inspection, we identified two clusters of traditions that emerged from the data: (1) Hindu meditative traditions, also including Sufi and Tibetan meditators; and (2) Buddhist meditative traditions, also including Christian and Qigong/Tai Chi meditators. However, Qigong/Tai Chi meditators are relatively far from the remaining traditions in the Buddhist cluster. Within the Hindu cluster, one could differentiate a yoga cluster and a broader Hindu cluster, yet the distances between these two clusters are rather short. 
These results support the general commonalities identified in the analyses above while at the same time substantiating the distinctions found between Hindu and Buddhist meditators. Interestingly, Tibetan Buddhism appeared within the Hindu cluster. This might be indicative of shared preferences in these two groups reflecting their shared past. Tibetan Buddhism incorporates many Hindu contemplative practices that other Buddhist traditions such as Zen and Theravada do not (Powers, 2007; Rinpoche Dagsay Tulku, 2002).

Last, we had a closer look at distinctive meditation techniques that appeared solely in the top-10 list of one specific tradition but in no other ranking sequence. We identified 12 distinctive techniques in six diverse traditions (see Table B6 in the Supplementary Material). In most cases, these techniques corresponded to the recollections of our interview participants in Study 1 who practiced in these specific traditions, except for Qigong/Tai Chi meditators. However, this might also be due to the relatively small subgroup of Qigong/Tai Chi meditators $(n=5)$ in our sample.

In conclusion, traditions do differ in their preferences for specific meditation techniques, and this diversity should be taken into account more. Although there are many overlapping preferences, there is a multiplicity of techniques that are tradition specific and, often, underresearched in contemplative sciences.

Once we identified what meditators did when they meditated in various meditative traditions, we were interested in how these techniques might be clustered together. Therefore, we conducted a series of cluster analyses to find groups of related techniques that were commonly practiced together.

\section{What Do Meditators Do When They Meditate: The Combinations}

Meditators often use several meditation techniques when they practice. They might have a main practice and alternate it from time-to-time with other practices. Alternatively, they might have a certain set of techniques that are practiced in a predefined sequence, or depending on the time of day or a specific intention they have. Consequently, we were interested to find groups of techniques that are commonly practiced together. To identify groups of related meditation techniques, we performed three hierarchical cluster analyses. These analyses relied on all 50 
meditation techniques and complement the top-10 analyses described above. Hence, we first clustered the ratings of all 635 participants. Second, we performed two separate cluster analyses for the two largest subgroups of participants, namely, Buddhist and Hindu meditators. In accordance with our previous descriptive analyses, we would expect marked differences between clusters of Buddhist and Hindu meditators.

Prior to each cluster analysis, we calculated Euclidean distances between the ratings of each meditation technique across all participants or across participants within each of the two subgroups in question. Then, we submitted the distance measures to a Ward's hierarchical agglomerative cluster analysis and visually inspected the resulting dendrograms. Figure 3 depicts the dendrogram of the overall cluster solution. Meditation techniques with similar experience ratings have shorter bars and appear closer to each other in the dendrogram. Accordingly, these meditation techniques are commonly practiced together by meditators in our sample. Longer bars, on the other hand, represent greater distances between practiced meditation techniques and point to differences in the combination of certain techniques. 


\section{Figure 3}

Dendrogram of Relative Distances Between Experience Ratings of 50 Basic Meditation Techniques Across All Meditators ( $\mathrm{n}=635)$

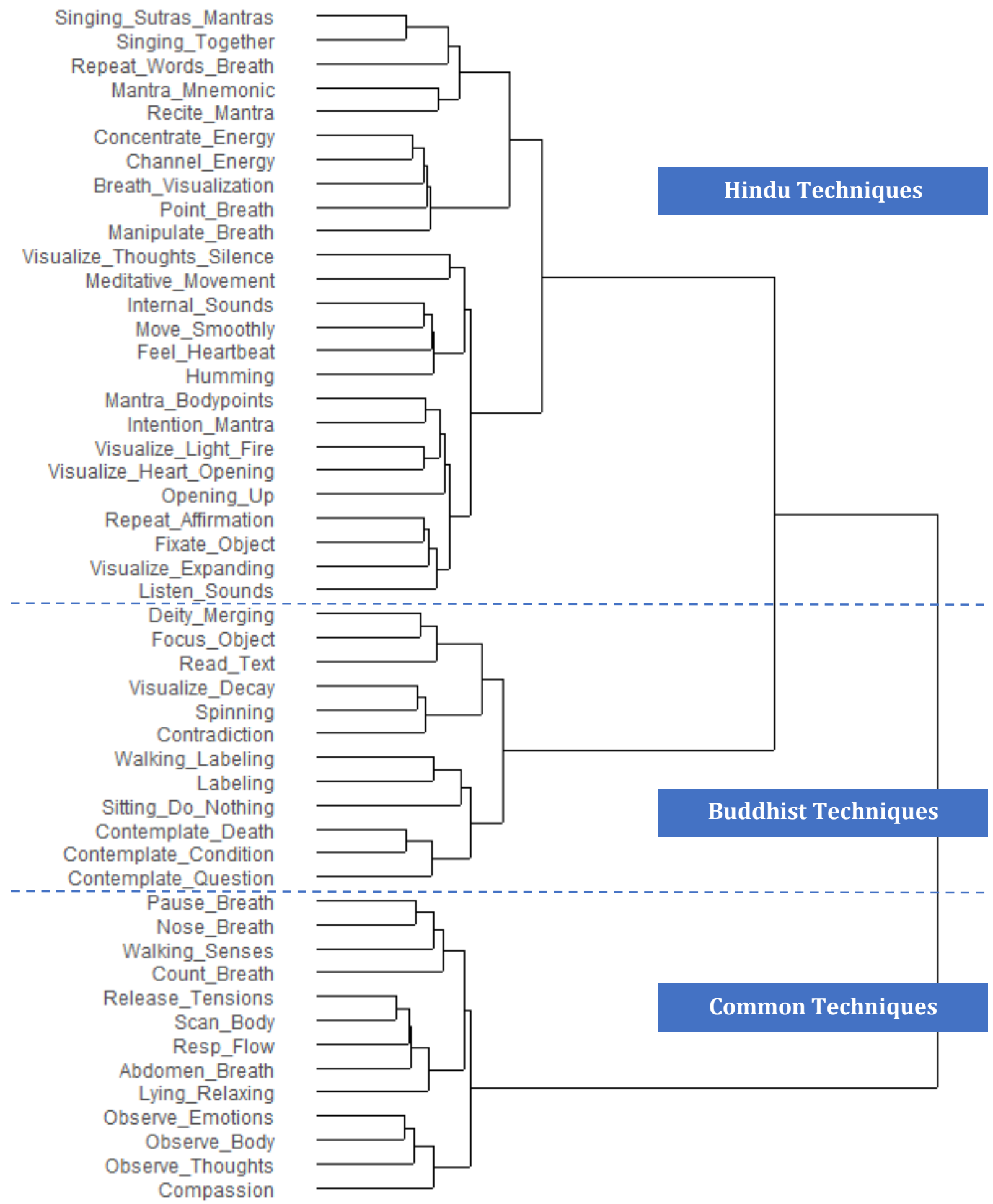

Note. Blue dashed lines represent the partitioning of three clusters. See Table 1 for descriptions of technique codes. 
Looking at Figure 3, three main clusters of techniques emerged from the data. We named them according to the context in which they are commonly practiced together-from top to bottom: (1) Hindu meditation techniques, (2) Buddhist meditation techniques, and (3) common meditation techniques.

We found meditation techniques summarized in the Hindu cluster both in the recollections from expert meditators in Study 1 as well as in the top positions in the ranking sequences of many Hindu traditions. The same is true for most of the techniques found in the Buddhist cluster. The last cluster, though, is different. It comprises many of the very common, more general techniques we located in many different traditions. A majority of these have a strong and prominent focus on the body. Although they correspond closely to the abovementioned top10 list of Buddhist meditators, we nevertheless decided to call them "common" meditation techniques. This was done because all of these techniques are widely known and utilized in many different contexts, including traditional schools as well as secular meditation programs such as (Kabat-Zinn, 2013).

All clusters could be divided into smaller subclusters. However, the distances between these subclusters are markedly shorter than the distances between the larger clusters. One could section the Hindu cluster into three subclusters: (a) mantra meditation, (b) energy meditation, and (c) visualization and movement meditation. The Buddhist cluster is not as easy to subdivide. One subcluster could be named "contemplation," but it is difficult to find suitable names for other possible clusters. The common cluster could be segmented into (a) body-centered meditation and (b) mindful observation and compassion/virtue meditation. Yet, the lengths of the lines in the dendrogram would suggest a three-subcluster solution that we could not make sense of.

Subsequently, we conducted two cluster analyses for Buddhist and Hindu meditators to check for possible differences in clustering. This seemed plausible according to our abovementioned top-10 analyses. Figures 4 and 5 give the respective dendrograms. 


\section{Figure 4}

Dendrogram of Relative Distances Between Experience Ratings of 50 Basic Meditation Techniques Across Buddhist Meditators ( $\mathrm{n}=216$ )

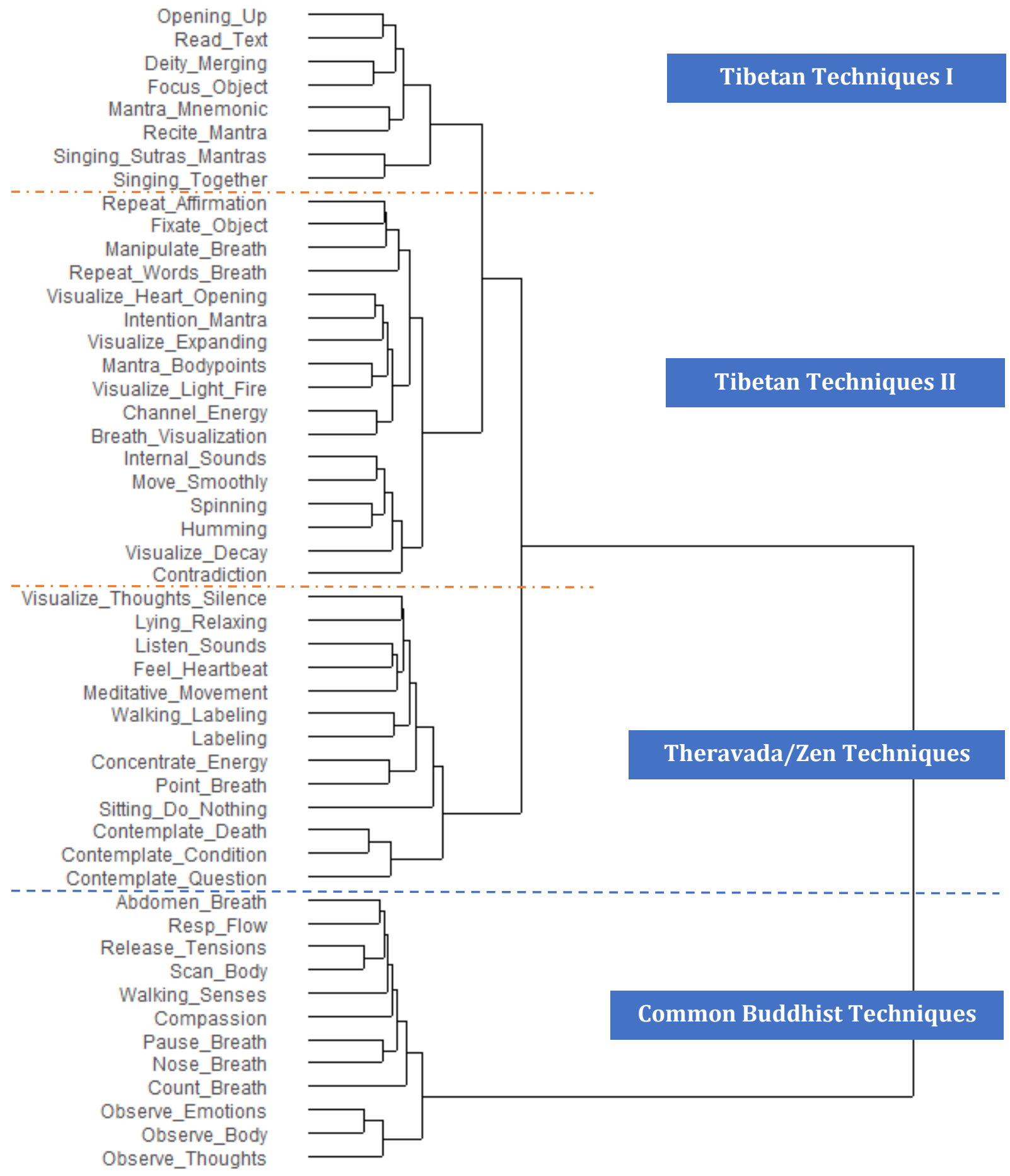

Note. Blue dashed lines represent the partitioning of two main clusters. Orange dot-dashed lines represent the partitioning of three subclusters within the larger cluster. See Table 1 for definitions of technique codes. 


\section{Figure 5}

Dendrogram of Relative Distances Between Experience Ratings of 50 Basic Meditation Techniques Across Hindu Meditators ( $\mathrm{n}=204)$

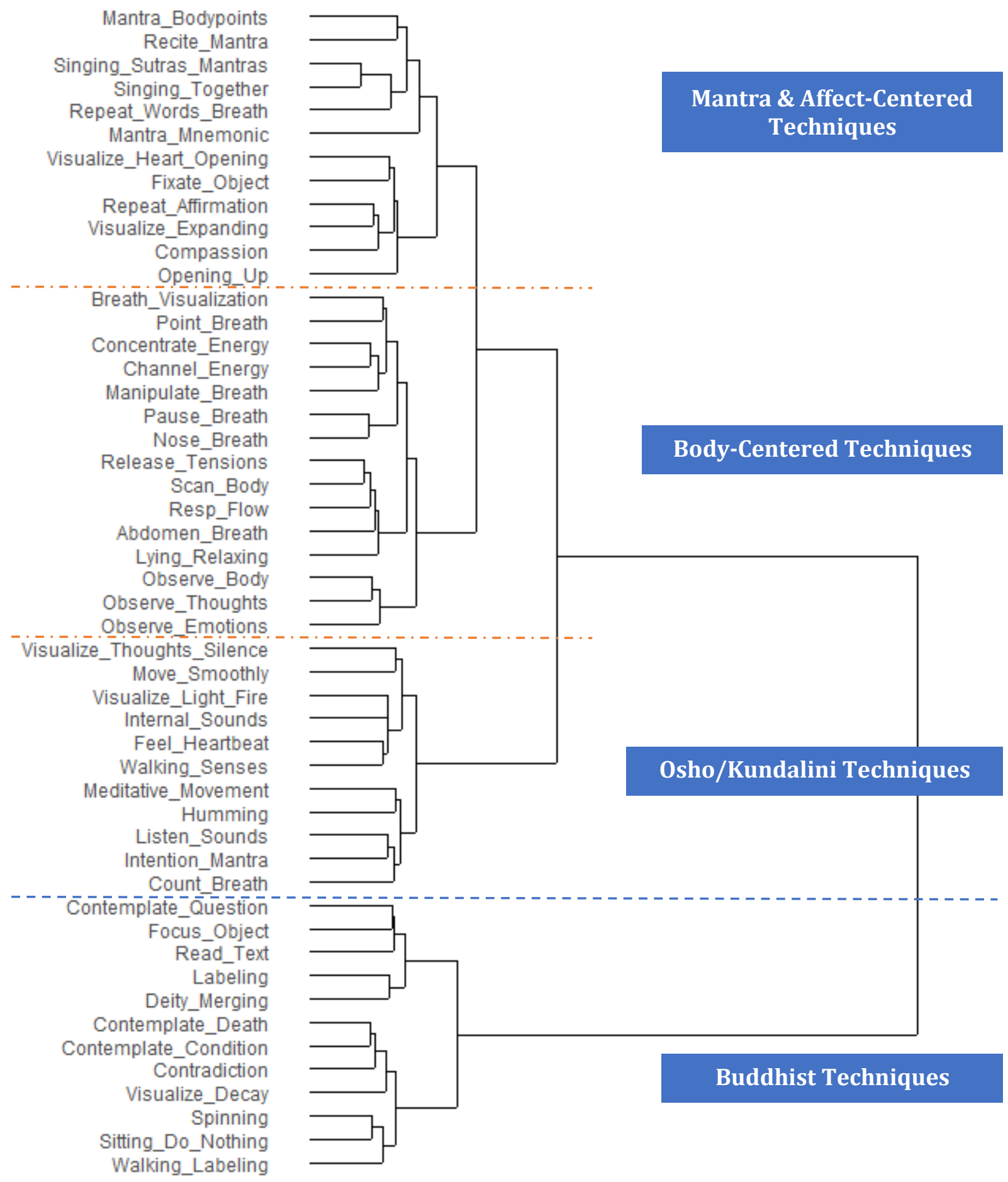

Note. Blue dashed lines represent the partitioning of two main clusters. Orange dot-dashed lines represent the partitioning of three subclusters within the larger cluster. See Table 1 for definitions of technique codes. 
The first thing that catches the eye in both figures is the presence of two distinct clusters, one smaller and one larger, with the larger cluster being subdivided into three subclusters. Interestingly, the smaller cluster in the dendrogram of Buddhist meditators very closely resembles the cluster of "common" meditation techniques in the overall solution, whereas the smaller cluster in the Hindu dendrogram is identical to the Buddhist cluster. We look into these findings more closely in the following.

The large cluster within the dendrogram of Buddhist meditators can be subdivided into three smaller subclusters. The first two of these subclusters represent a more Tibetan style of practice including a lot of mantra, visualization, and energy meditation techniques. The third subcluster, though, resembles a more Theravada or Zen style of practice, including labeling, contemplation, and sitting in silence. Hence, the larger cluster indicates specific differences between various schools of Buddhism, whereas the smaller cluster at the bottom represents techniques practiced by all Buddhist meditators, irrespective of their particular school.

Conversely, the clustering within the dendrogram of Hindu meditators looks markedly different. The larger cluster can be segmented into three subclusters. The first subcluster contains diverse forms of mantra and affect-centered meditation. The second cluster resembles the secular cluster in the overall solution but includes more breath and body-centered meditation techniques. The third subcluster includes meditation techniques with movement or sound and other techniques than are commonly practiced in Osho or Kundalini Yoga traditions. Accordingly, the first two subclusters represent meditation techniques commonly practiced in many Hindu traditions, whereas the third subcluster is indicative of two specific traditions. Conversely, the smaller cluster at the bottom represents distinguished Buddhist meditation techniques that are very uncommon in Hindu meditation practice.

Overall, these two tradition-specific cluster solutions provide unique insight into which techniques are commonly practiced together within two broad groups of Hindu and Buddhist meditators. They reveal clusters of techniques that can be easily attributed to particular schools within these traditions, as well as clusters of techniques commonly practiced by all Buddhist or 
Hindu meditators. Some clusters closely resemble clusters found in the overall solution, while others distinctly differ. Thus, these findings support the presence of both generally practiced meditation techniques and tradition-specific preferences for specific techniques and combinations of techniques. Consequently, they fit in neatly with the results described earlier in this paper. In summary, our findings depict a remarkable diversity of meditation techniques that should more often be taken into account.

\section{Discussion}

This study thoroughly evaluated the selection of 50 basic techniques that we had identified in Study 1. Altogether 635 experienced meditators responded to our online survey and provided data on how much experience they had with each of the 50 techniques. Moreover, they were invited to add any technique they considered missing on the list.

From the responses of our remarkably large and diverse sample of experienced meditators, we conclude that our selection of meditation techniques is comprehensive and representative for this sample. All 50 basic meditation techniques were commonly practiced and each technique had a notable number of participants who had a lot of experience with it. This was also true for less well known techniques that many people do not habitually associate with meditation. A small adjustment to the original list led to a final set of 52 basic meditation techniques.

An assessment of the 10 most popular meditation techniques across all meditators reveals a certain preponderance of Buddhist and Hindu meditation techniques. This is unsurprising as these two groups formed the majority of our sample. However, comparing the preferred techniques of Buddhist versus Hindu meditators, clear-cut distinctions between these two traditions become obvious. Of the 10 most popular techniques, they had only three in common, all focusing on the body or the breath. All other techniques differed.

This result recurred in the comparison of the preferences for 12 major meditative traditions. All 12 traditions had at least one preferred technique in common with each other tradition, the mean overlap being substantially higher particularly between related traditions. A 
subsequent cluster analysis revealed two clusters of traditions-Hindu traditions including Tibetan and Sufi meditators, and Buddhist traditions including Christian and Qigong/Tai Chi meditators. This indicates some shared preferences between otherwise less related traditions. Moreover, it provides more evidence for the existence of discernible differences between Buddhist and Hindu meditators.

A closer look revealed three very popular techniques that reappeared in the top ratings of almost all 12 traditions. All three techniques were body centered, pointing to an extraordinary relevance of body-centered techniques throughout all meditative traditions. Additionally, we uncovered a great variety of meditation techniques that are commonly used in diverse traditions but are, unfortunately, consistently underrepresented in contemplative research.

Often, meditators use several techniques in their meditation practice, consecutively or alternately. Commonly, these techniques reflect the teachings of a certain tradition. However, frequently, they also indicate the practice history of the meditator and the resulting preferences they developed over the course of time. Employing hierarchical cluster analysis, we found three large clusters of meditation techniques that are commonly practiced together. Again, there was an obvious divergence between clearly Buddhist and clearly Hindu meditation clusters. Conversely, the third cluster represented the aforementioned overarching meditation techniques spanning many meditative traditions. It included body-centered techniques as well as mindful observing and compassion/loving-kindness techniques. Two tradition-wise cluster analyses across purely Buddhist and purely Hindu meditators substantiated the presence of this general cluster in both traditions. Furthermore, both cluster analyses uncovered clusters of techniques relevant for specific subgroups of Buddhist or Hindu traditions. These clusters corresponded to our previous analyses, suggesting a greater differentiation between diverse meditative practices and traditions. Consequently, the consistent findings across a multitude of analyses increase the convergent validity of our results. 


\section{The Central Role of Body-Centered Meditation Techniques}

Some studies comparing the effects of different meditation techniques found that breathing meditation or the body scan were experienced as less effortful and easier to learn than other techniques (Kropp \& Sedlmeier, 2019; Lumma et al., 2015). Conventionally, many meditative traditions emphasize the central role of the body in meditation and recommend learning to observe the breath or the body to beginners of meditation (Ott, 2010; Sedlmeier, 2016; Shear, 2006). Accordingly, meditators in the present study, with all sorts of meditative backgrounds, preferred to place their attention on their body or basic bodily processes such as the breath. This is true even though they had experience with many other meditation techniques, too. Moreover, clusters of body-centered meditation techniques recurred in all analyses presented in this paper. Consequently, it seems that body-centered meditation techniques are of profound importance for general meditation practice.

Some studies found significant increases in body awareness or interoception (the processing of internal bodily signals) when participants practiced body-centered techniques compared to an active control activity (Fischer et al., 2017) or other meditation techniques (Kok \& Singer, 2017). Developing a greater sense of body awareness and interoception has been proposed as one of the central mechanisms of meditation and mindfulness (Cebolla et al., 2016; Farb et al., 2015; Gibson, 2019; Hölzel et al., 2011). Furthermore, the insular cortex has been reliably associated with interoceptive processes (Craig, 2003). Fittingly, neuroscientific studies have shown consistent structural alterations and functional activations in the insular cortex across many different kinds of meditation (Fox et al., 2014, 2016). Thus, it seems that the focus on the body inherent in many diverse meditation techniques, but specifically in body-centered techniques, is one of the key aspects of meditation practice. This is in line with current literature emphasizing the embodied nature of meditation (Cebolla et al., 2016; Kerr et al., 2013; Khoury et al., 2017; Michalak et al., 2012; Varela et al., 2017).

A recent empirical classification system (Matko \& Sedlmeier, 2019) identified two embodied dimensions along which meditation techniques could be classified. The authors posited 
that all meditation techniques share a somatic component and are inherently embodied. This might also apply to our selection of 52 meditation techniques. Many, if not all, meditation practices emphasize directing attention to interoceptive signals. Whether meditators visualize their heart opening like a rose blossom, focus on internal sounds and vibrations, or gaze at the wall and observe themselves doing nothing, the body remains a constant companion in all their endeavors. This may be less evident for techniques consisting of contemplating a spiritually important question or reading certain paragraphs of a text repeatedly. Nevertheless, even contemplation and reading are done with the intention to observe one's internal reactions to the content of the text or the contemplative question. Thus, it might well be that all meditation techniques are embodied.

\section{Measuring Up to the Diversity of Meditation Practice}

In their classification system, Matko and Sedlmeier (2019) detected seven clusters of similar meditation techniques, namely, mindful observation, body-centered meditation, visual concentration, contemplation, affect-centered meditation, mantra meditation, and meditation with movement. All of these clusters were also present in the current study, albeit in different combinations. It seems that meditators in this study combined techniques from several clusters of similar techniques, presumably to maximize the diversity of effects associated with these varying techniques. This appears perfectly reasonable, as meditators might practice certain sets of meditation techniques, often jointly taught by certain traditions, but for a whole range of different purposes.

Many traditions formulate guidelines about when to use which technique. Some traditions differentiate between practices for beginner and those for advanced meditators (Anālayo, 2003; Mahasi, 1970). Some even provide specific meditation techniques connected to achieving certain goals or treating certain psychological or somatic conditions (ShannahoffKhalsa, 2004). Some advise meditators on which techniques to use based on a prior assessment of their personality (Kornfield, 2009). However, actual scientific evidence for many of these claims is still scarce, and future investigations should address these issues. Additionally, more research 
is needed to effectively disentangle similarities, effects, and purposes of diverse meditation techniques.

The most popular techniques identified in this study quite clearly depict the most well known and most researched groups of meditative practices, that is, the body scan (Dambrun et al., 2019), observing the breath (Doll et al., 2016), observing thoughts (Lumma et al., 2015), cultivating compassion or loving-kindness (May et al., 2014), and mantra meditation (Lynch et al., 2018). Nonetheless, the repeatedly observed evident differences between Buddhist and Hindu meditation practices call for closer inspection. Currently, the focus of contemplative research lies predominantly on mindfulness meditation (Rose et al., 2020), with other meditation techniques, especially from Hindu traditions, receiving a lot less attention. However, as Hindu meditation techniques differ so strikingly from Buddhist techniques, they should be investigated in more detail.

In light of the remarkable diversity of meditation techniques found in the present study, definitions of meditation should be reconsidered. All definitions brought up so far indicate a great variance in possible approaches to defining meditation and a lack of consensus among experts (Bond et al., 2009; Lutz et al., 2008; Nash \& Newberg, 2013; Tang et al., 2015; Walsh \& Shapiro, 2006; West, 2016). It would be advisable to include the embodied aspect of meditation in future definitions of meditation. It also might even be conceivable to establish different terms and definitions for various forms of meditation. With this, researchers could contribute to a more differentiated use of the umbrella term "meditation."

\section{Limitations and Future Directions}

We are well aware that our choice of meditation techniques might have been limited to the regional availability of meditation teachers and traditions in Study 1. Still, the adequateness and probably also the comprehensiveness of our selection was confirmed by a broad sample of experienced meditators with a diversity of meditative backgrounds almost unique in contemplative research. Although most meditators belonged to some Buddhist or Hindu tradition, we also reached smaller groups of meditative traditions, such as Christian, Sufi, or Qigong 
meditators. We know of only one study that addressed a similarly large and diverse sample of experienced meditators (Vieten et al., 2018). Clearly, our sample cannot be regarded as being representative of Western European, let alone all, experienced meditators practicing the abovementioned meditation techniques. We encourage researchers to evaluate our selection of 52 meditation techniques in other countries and contexts to examine its general validity.

The sample sizes of some traditions were relatively small, especially for Osho, Christian, MBSR, and Qigong meditators. Furthermore, many meditators drew their meditation practices from several backgrounds or had a whole history of practicing in different traditions. It was, thus, difficult for us to determine the major tradition of some participants. Consequently, future studies should ask meditators to distinguish their major meditative tradition from possible adjunct practices explicitly. They should also approach meditators from the abovementioned, underrepresented meditative traditions.

One could argue that the 52 techniques that we evaluated in this study were artificially constructed and taken out of context. Traditionally, meditation techniques are practiced in a specific sequence, in the framework of a specific tradition, or in combination with other practices. Observing the breath, for example, is often combined with visualizations or with the repetition of a mantra. Conversely, little is known about the effects of combined meditation techniques compared to simple techniques. Therefore, it seems promising to investigate and compare simple and combined techniques, to see if there are, indeed, any additive effects.

Furthermore, a specific traditional background or framework can tremendously influence the effects of meditation (Amihai \& Kozhevnikov, 2014; Bayot et al., 2020; Wachholtz \& Pargament, 2005). However, these effects may be very complex, specifically regarding the manifold meditation traditions. In an attempt to simplify this issue, we chose to deduce basic meditation techniques practiced in many meditative traditions. This might help clarify and disentangle genuine effects of simple meditation techniques from the effects of their traditional context. Future studies could compare the effects of bare meditation techniques to a combined intervention of meditation practice and ethical or philosophical teachings. 
Although we now have a better idea of what meditators do when they are meditating, or rather, which meditation techniques they employ, we have little access to the experiences they have during meditation. Several authors have pointed out the difference between meditative technique and meditative state or phenomenological experience (Bond et al., 2009; Nash \& Newberg, 2013). Phenomenological experiences are difficult to capture and depend strongly on individual factors, such as personality or learning history (B. K. Hölzel et al., 2011; Lippelt et al., 2014; May et al., 2014; Schmidt, 2014; R. Tang \& Braver, 2020). It seems, for example, that people who score high on the trait absorption tend to experience deep meditative states and intense feelings of self-transcendence more easily (Hölzel \& Ott, 2006; Lifshitz et al., 2019). Furthermore, phenomenological experience also differs across diverse meditation techniques (Przyrembel \& Singer, 2018). Recently, Lutz and colleagues (2015) proposed a phenomenological matrix to help describe different states and processes related to mindfulness practices. Future studies could investigate phenomenological experiences associated with the practice of a larger sample of meditation techniques and focus on possible interactions with personality factors, too. Single-case research designs (Barlow et al., 2009) seem to be a promising approach in this respect (May et al., 2014).

In the long run, all of these efforts could contribute to establishing one or more theories of meditation. This endeavor is not only imperative for the future of scientific research into meditation (Sedlmeier et al., 2014, 2016) but also highly promising in efforts to understand the phenomenon of meditation (or the phenomena of different kinds of meditations) more thoroughly.

\section{Conclusion}

The aim of this paper was to shed light on the manifold practices meditators use when they meditate. To do so, we employed a bottom-up methodological approach by first gathering, then reducing, and finally evaluating a large sample of diverse meditation techniques. Throughout this process, we relied on the statements and ratings of expert meditators and used qualitative and quantitative methods to arrive at a reliable and valid consensus. 
While Study 1 generated a selection of 50 basic meditation techniques, Study 2 provided valuable insight into the prevalence and popularity of these techniques in manifold meditative traditions. The two studies presented in this paper provide converging evidence for the immense variety of techniques that can be subsumed under the umbrella term "meditation." Thereby, they add to a growing body of research on diversifying meditation. Future definitions of meditation should take the multiplicity of meditation techniques and their embodied aspect into consideration. We hope that our diverse collection of basic meditation techniques will be useful for future comparative and differential studies and the development of profound theories of meditation. 


\section{References}

Adyashanti. (2006). True meditation: Discover the freedom of pure awareness. Sounds True.

Allbritton, M., \& Heeter, C. (2018). Meditation as an intervention for health: A framework for understanding meditation research. OBM Integrative and Complementary Medicine, 3(4). https://doi.org/10.21926/obm.icm.1804025

Amihai, I., \& Kozhevnikov, M. (2014). Arousal vs. relaxation: A comparison of the neurophysiological and cognitive correlates of Vajrayana and Theravada meditative practices. PloS One, 9(7), Article e102990. https://doi.org/10.1371/journal.pone.0102990

Anālayo. (2003). Satipațțāna: The direct path to realization. Windhorse Publications.

Austin, J. H. (1998). Zen and the brain. MIT Press.

Awasthi, B. (2013). Issues and perspectives in meditation research: In search for a definition. Frontiers in Psychology, 3, Article 613. https://doi.org/10.3389/fpsyg.2012.00613

Bach, J. M., \& Guse, T. (2015). The effect of contemplation and meditation on 'great compassion'on the psychological well-being of adolescents. The Journal of Positive Psychology, 10(4), 359369.

Bansal, A., Mittal, A., \& Seth, V. (2016). Osho Dynamic Meditation's effect on serum cortisol level. Journal of Clinical and Diagnostic Research, 10(11), CC05. https://doi.org/10.7860/JCDR/2016/23492.8827

Barlow, D. H., Nock, M., \& Hersen, M. (2009). Single case experimental designs: Strategies for studying behavior for change (3rd ed.). Pearson.

Bäumer, B. (2008). Vijñāna Bhairava-Das göttliche Bewusstsein: 112 Weisen der mystischen Erfahrung im Śivaismus von Kashmir. Verlag der Weltreligionen.

Bayot, M., Vermeulen, N., Kever, A., \& Mikolajczak, M. (2020). Mindfulness and empathy: Differential effects of explicit and implicit Buddhist teachings. Mindfulness, 11(1), 5-17. https://doi.org/10.1007/s12671-018-0966-4

Benson, H. (1975). The relaxation response. Morrow.

Bodian, S. (2016). Meditation for dummies. John Wiley \& Sons. 
Bond, K., Ospina, M. B., Hooton, N., Bialy, L., Dryden, D. M., Buscemi, N., Shannahoff-Khalsa, D., Dusek, J., \& Carlson, L. E. (2009). Defining a complex intervention: The development of demarcation criteria for "meditation." Psychology of Religion and Spirituality, 1(2), 129. https://doi.org/10.1037/a0015736

Brandmeyer, T., Delorme, A., \& Wahbeh, H. (2019). The neuroscience of meditation: Classification, phenomenology, correlates, and mechanisms. In N. Srinivasan (Ed.), Progress in brain research (Vol. 244, pp. 1-29). Elsevier. https://doi.org/10.1016/bs.pbr.2018.10.020

Burke, A. (2012). Comparing individual preferences for four meditation techniques: Zen, Vipassana (mindfulness), Qigong, and Mantra. Explore: The Journal of Science and Healing, 8(4), 237-242. https://doi.org/10.1016/j.explore.2012.04.003

Cakmak, Y. O., Ekinci, G., Heinecke, A., \& Çavdar, S. (2017). A possible role of prolonged whirling episodes on structural plasticity of the cortical networks and altered vertigo perception: The cortex of sufi whirling dervishes. Frontiers in Human Neuroscience, 11. https://doi.org/10.3389/fnhum.2017.00003

Cebolla, A., Campos, D., Galiana, L., Oliver, A., Tomás, J. M., Feliu-Soler, A., Soler, J., García-Campayo, J., Demarzo, M., \& Baños, R. M. (2017). Exploring relations among mindfulness facets and various meditation practices: Do they work in different ways? Consciousness and Cognition, 49, 172-180. https://doi.org/10.1016/j.concog.2017.01.012

Cebolla, A., Miragall, M., Palomo, P., Llorens, R., Soler, J., Demarzo, M., García-Campayo, J., \& Baños, R. M. (2016). Embodiment and body awareness in meditators. Mindfulness, 7(6), 12971305. https://doi.org/10.1007/s12671-016-0569-x

Chiesa, A., \& Malinowski, P. (2011). Mindfulness-based approaches: Are they all the same? Journal of Clinical Psychology, 67(4), 404-424. https://doi.org/10.1002/jclp.20776

Chinmoy, S. (2013). Meditation. Golden Shore.

Colzato, L. S., Szapora, A., \& Hommel, B. (2012). Meditate to create: The impact of focused-attention and open-monitoring training on convergent and divergent thinking. Frontiers in Psychology, 3, Article 116. https://doi.org/10.3389/fpsyg.2012.00116 
Craig, A. D. (2003). Interoception: The sense of the physiological condition of the body. Current Opinion in Neurobiology, 13(4), 500-505. https://doi.org/10.1016/S09594388(03)00090-4

Dahl, C. J., Lutz, A., \& Davidson, R. J. (2015). Reconstructing and deconstructing the self: Cognitive mechanisms in meditation practice. Trends in Cognitive Sciences, 19(9), 515-523. https://doi.org/10.1016/j.tics.2015.07.001

Dambrun, M., Berniard, A., Didelot, T., Chaulet, M., Droit-Volet, S., Corman, M., Juneau, C., \& Martinon, L. M. (2019). Unified consciousness and the effect of body scan meditation on happiness: Alteration of inner-body experience and feeling of harmony as central processes. Mindfulness, 10(8), 1530-1544. https://doi.org/10.1007/s12671-019-01104-y

de Vries, A., \& Ripley, B. D. (2020). ggdendro: Create dendrograms and tree diagrams using "ggplot2" (R package version 0.1.22) [Computer software]. https://CRAN.R-project.org/package=ggdendro

Deshmukh, V. D. (2006). Neuroscience of meditation. The Scientific World Journal, 6, 2239-2253. https://doi.org/10.1100/tsw.2006.353

Doll, A., Hölzel, B. K., Mulej Bratec, S., Boucard, C. C., Xie, X., Wohlschläger, A. M., \& Sorg, C. (2016). Mindful attention to breath regulates emotions via increased amygdala-prefrontal cortex connectivity. NeuroImage, 134, 305-313. https://doi.org/10.1016/j.neuroimage.2016.03.041

Dorjee, D. (2016). Defining contemplative science: The metacognitive self-regulatory capacity of the mind, context of meditation practice and modes of existential awareness. Frontiers in Psychology, 7, Article 1788. https://doi.org/10.3389/fpsyg.2016.01788

Farb, N., Daubenmier, J., Price, C. J., Gard, T., Kerr, C., Dunn, B. D., Klein, A. C., Paulus, M. P., \& Mehling, W. E. (2015). Interoception, contemplative practice, and health. Frontiers in Psychology, 6, Article 763. https://doi.org/10.3389/fpsyg.2015.00763

Feldman, G., Greeson, J., \& Senville, J. (2010). Differential effects of mindful breathing, progressive muscle relaxation, and loving kindness meditation on decentering and negative reactions 
to repetitive thoughts. Behaviour Research and Therapy, 48(10), 1002-1011. https://doi.org/10.1016/j.brat.2010.06.006

Fischer, D., Messner, M., \& Pollatos, O. (2017). Improvement of interoceptive processes after an 8week body scan intervention. Frontiers in Human Neuroscience, 11, Article 452. https://doi.org/10.3389/fnhum.2017.00452

Fox, K. C. R., Dixon, M. L., Nijeboer, S., Girn, M., Floman, J. L., Lifshitz, M., Ellamil, M., Sedlmeier, P., \& Christoff, K. (2016). Functional neuroanatomy of meditation: A review and meta-analysis of 78 functional neuroimaging investigations. Neuroscience \& Biobehavioral Reviews, 65, 208-228. https://doi.org/10.1016/j.neubiorev.2016.03.021

Fox, K. C. R., Nijeboer, S., Dixon, M. L., Floman, J. L., Ellamil, M., Rumak, S. P., Sedlmeier, P., \& Christoff, K. (2014). Is meditation associated with altered brain structure? A systematic review and meta-analysis of morphometric neuroimaging in meditation practitioners. Neuroscience \& Biobehavioral Reviews, 43, 48-73. https://doi.org/10.1016/j.neubiorev.2014.03.016

Gibson, J. (2019). Mindfulness, interoception, and the body: A contemporary perspective. Frontiers in Psychology, 10, Article 2012. https://doi.org/10.3389/fpsyg.2019.02012

Goyal, M., Singh, S., Sibinga, E. M., Gould, N. F., Rowland-Seymour, A., Sharma, R., Berger, Z., Sleicher, D., Maron, D. D., \& Shihab, H. M. (2014). Meditation programs for psychological stress and well-being: A systematic review and meta-analysis. JAMA Internal Medicine, 174(3), 357-368. https://doi.org/10.1001/jamainternmed.2013.13018

Gul, L., \& Jahangir, S. F. (2019). The effectiveness of mindfulness-based stress reduction programme (MBSRP) and sufi meditation (SM) in the treatment of neurotic anxiety among females. FWU Journal of Social Sciences, 13(1), 120-130.

Harne, B. P., Tahseen, A. A., Hiwale, A. S., \& Dhekekar, R. S. (2019). Survey on Om meditation: Its effects on the human body and Om meditation as a tool for stress management. Psychological Thought, 12(1). https://doi.org/10.5964/psyct.v12i1.275

Hölzel, B. K., Lazar, S. W., Gard, T., Schuman-Olivier, Z., Vago, D. R., \& Ott, U. (2011). How does mindfulness meditation work? Proposing mechanisms of action from a conceptual and 
neural perspective. Perspectives on Psychological Science, 6(6), 537-559. https://doi.org/10.1177/1745691611419671

Hölzel, B., \& Ott, U. (2006). Relationships between meditation depth, absorption, meditation practice, and mindfulness: A latent variable approach. Journal of Transpersonal Psychology, 38(2), 179-199.

Hunt, M., Al-Braiki, F., Dailey, S., Russell, R., \& Simon, K. (2018). Mindfulness training, yoga, or both? Dismantling the active components of a mindfulness-based stress reduction intervention. Mindfulness, 9(2), 512-520. https://doi.org/10.1007/s12671-017-0793-z

Isbel, B., \& Summers, M. J. (2017). Distinguishing the cognitive processes of mindfulness: Developing a standardised mindfulness technique for use in longitudinal randomised control trials. Consciousness and Cognition, 52, 75-92. https://doi.org/10.1016/j.con$\operatorname{cog} \cdot 2017.04 .019$

Josipovic, Z. (2010). Duality and nonduality in meditation research. Consciousness and Cognition, 19(4), 1119-1121. https://doi.org/10.1016/j.concog.2010.03.016

Kabat-Zinn, J. (2013). Full catastrophe living: How to cope with stress, pain and illness using mindfulness meditation (Rev. ed.). Piatkus.

Kaufman, L., \& Rousseeuw, P. J. (2009). Finding groups in data: An introduction to cluster analysis. John Wiley \& Sons.

Kerr, C. E., Sacchet, M. D., Lazar, S. W., Moore, C. I., \& Jones, S. R. (2013). Mindfulness starts with the body: Somatosensory attention and top-down modulation of cortical alpha rhythms in mindfulness meditation. Frontiers in Human Neuroscience, 7, Article 12. https://doi.org/10.3389/fnhum.2013.00012

Khoury, B., Knäuper, B., Pagnini, F., Trent, N., Chiesa, A., \& Carrière, K. (2017). Embodied mindfulness. Mindfulness, 8(5), 1160-1171.

Kjaer, T. W., Bertelsen, C., Piccini, P., Brooks, D., Alving, J., \& Lou, H. C. (2002). Increased dopamine tone during meditation-induced change of consciousness. Cognitive Brain Research, 13(2), 255-259. https://doi.org/10.1016/S0926-6410(01)00106-9 
Kok, B. E., \& Singer, T. (2017). Phenomenological fingerprints of four meditations: Differential state changes in affect, mind-wandering, meta-cognition, and interoception before and after daily practice across 9 months of training. Mindfulness, 8(1), 218-231. https://doi.org/10.1007/s12671-016-0594-9

Kornfield, J. (2009). The wise heart: A guide to the universal teachings of Buddhist psychology. Bantam.

Kropp, A., \& Sedlmeier, P. (2019). What makes mindfulness-based interventions effective? An examination of common components. Mindfulness. https://doi.org/10.1007/s12671-01901167-x

Lee, T. M., Leung, M.-K., Hou, W.-K., Tang, J. C., Yin, J., So, K.-F., Lee, C.-F., \& Chan, C. C. (2012). Distinct neural activity associated with focused-attention meditation and loving-kindness meditation. PLoS One, 7(8), Article e40054.

Leiner, D. J. (2019). SoSci Survey (Version 3.1.06) [Computer software]. https://www.soscisurvey.de

Lifshitz, M., van Elk, M., \& Luhrmann, T. M. (2019). Absorption and spiritual experience: A review of evidence and potential mechanisms. Consciousness and Cognition, 73, Article 102760. https://doi.org/10.1016/j.concog.2019.05.008

Lippelt, D. P., Hommel, B., \& Colzato, L. S. (2014). Focused attention, open monitoring and loving kindness meditation: Effects on attention, conflict monitoring, and creativity: A review. Frontiers in Psychology, 5, Article 1083. https://doi.org/10.3389/fpsyg.2014.01083

Lou, H. C., Kjaer, T. W., Friberg, L., Wildschiodtz, G., Holm, S., \& Nowak, M. (1999). A 150-H20 PET study of meditation and the resting state of normal consciousness. Human Brain Mapping, $7(2), 98-105$.

Lumma, A.-L., Kok, B. E., \& Singer, T. (2015). Is meditation always relaxing? Investigating heart rate, heart rate variability, experienced effort and likeability during training of three types of meditation. International Journal of Psychophysiology, 97(1), 38-45. https://doi.org/10.1016/j.ijpsycho.2015.04.017 
Lutz, A., Jha, A. P., Dunne, J. D., \& Saron, C. D. (2015). Investigating the phenomenological matrix of mindfulness-related practices from a neurocognitive perspective. American Psychologist, 70(7), 632-658. https://doi.org/10.1037/a0039585

Lutz, A., Slagter, H. A., Dunne, J. D., \& Davidson, R. J. (2008). Attention regulation and monitoring in meditation. Trends in Cognitive Sciences, 12(4), 163-169. https://doi.org/10.1016/j.tics.2008.01.005

Lynch, J., Prihodova, L., Dunne, P. J., Carroll, Á., Walsh, C., McMahon, G., \& White, B. (2018). Mantra Meditation for Mental Health in the General Population: A Systematic Review. European Journal of Integrative Medicine.

Mahasi, S. (1970). Practical Vipassana exercises. Buddha Dharma Education Association. http://www.buddhanet.net

Main, J. (2013). Word into silence: A manual for christian meditation. Canterbury Press.

Matko, K., \& Sedlmeier, P. (2019). What is meditation? Proposing an empirically derived classification system. Frontiers in Psychology, 10, Article 2276. https://doi.org/10.3389/fpsyg.2019.02276

May, C. J., Weyker, J. R., Spengel, S. K., Finkler, L. J., \& Hendrix, S. E. (2014). Tracking longitudinal changes in affect and mindfulness caused by concentration and loving-kindness meditation with hierarchical linear modeling. Mindfulness, 5(3), 249-258. https://doi.org/10.1007/s12671-012-0172-8

Michalak, J., Burg, J., \& Heidenreich, T. (2012). Don't forget your body: Mindfulness, embodiment, and the treatment of depression. Mindfulness, 3(3), 190-199. https://doi.org/10.1007/s12671-012-0107-4

Nandamalabhivamsa, A. (2013). Samatha und Vipassana. Konzentrations- und Einsichtsmeditation (A. Agganyani, Trans.). Centre for Buddhist Studies.

Nash, J. D., \& Newberg, A. (2013). Toward a unifying taxonomy and definition for meditation. Frontiers in Psychology, 4, Article 806. https://doi.org/10.3389/fpsyg.2013.00806

Osho, B. S. R. (1983). The orange book: The meditation techniques of Bhagwan Shree Rajneesh (2nd ed.). Rajneesh Foundation International. 
Ospina, M. B., Bond, K., Karkhaneh, M., Tjosvold, L., Vandermeer, B., Liang, Y., Bialy, L., Hooton, N., Buscemi, N., \& Dryden, D. M. (2007). Meditation practices for health: State of the research. In Evidence Report/Technology Assessment (Vol. 155, pp. 1-263).

Ott, U. (2010). Meditation für Skeptiker: Ein Neurowissenschaftler erklärt den Weg zum Selbst. O. W. Barth.

Peng, C.-K., Henry, I. C., Mietus, J. E., Hausdorff, J. M., Khalsa, G., Benson, H., \& Goldberger, A. L. (2004). Heart rate dynamics during three forms of meditation. International Journal of Cardiology, 95(1), 19-27. https://doi.org/10.1016/j.ijcard.2003.02.006

Pölönen, P., Lappi, O., \& Tervaniemi, M. (2019). Effect of meditative movement on affect and flow in Qigong practitioners. Frontiers in Psychology, 10, Article 2375. https://doi.org/10.3389/fpsyg.2019.02375

Powers, J. (2007). Introduction to Tibetan Buddhism (Rev. ed.). Snow Lion.

Przyrembel, M., \& Singer, T. (2018). Experiencing meditation: Evidence for differential effects of three contemplative mental practices in micro-phenomenological interviews. Consciousness and Cognition, 62, 82-101.

R Core Team. (2020). R: A language and environment for statistical computing. R Foundation for Statistical Computing. https://www.R-project.org/

Reddy, J. S. K., \& Roy, S. (2019). Understanding meditation based on the subjective experience and traditional goal: Implications for current meditation research. Frontiers in Psychology, 10, Article 1827. https://doi.org/10.3389/fpsyg.2019.01827

Rinpoche Dagsay Tulku. (2002). The practice of Tibetan Meditation: Exercises, visualizations, and mantras for health and well-being. Inner Traditions/Bear \& Co.

Rose, S., Zell, E., \& Strickhouser, J. E. (2020). The effect of meditation on health: A metasynthesis of randomized controlled trials. Mindfulness, 11(2), 507-516. https://doi.org/10.1007/s12671-019-01277-6

Saradananda, S. (2011). The essential guide to chakras: Discover the healing power of chakras for mind, body, and spirit. Watkins.

Schimmel, A. (1992). Mystische Dimension des Islam. Die Geschichte des Sufismus. Insel Verlag. 
Schmidt, S. (2014). Opening up meditation for science: The development of a meditation classification system. In S. Schmidt \& H. Walach (Eds.), Meditation-Neuroscientific approaches and philosophical implications. Studies in neuroscience, consciousness and spirituality (Vol. 1-2, pp. 137-152). Springer.

Sedlmeier, P. (2016). Die Kraft der Meditation: Was die Wissenschaft darüber weiß. Rowohlt Polaris.

Sedlmeier, P., Eberth, J., \& Puta, M. (2016). Meditation: Future theory and research. In M. A. West (Ed.), The psychology of meditation: Research and practice (pp. 285-310). Oxford University Press.

Sedlmeier, P., Eberth, J., \& Schwarz, M. (2014). Meta-analyses and other methodological issues in meditation research: Reply to Orme-Johnson and Dillbeck (2014). Psychological Bulletin, 140(2), 617-622. https://doi.org/10.1037/a0035896

Sedlmeier, P., Eberth, J., Schwarz, M., Zimmermann, D., Haarig, F., Jaeger, S., \& Kunze, S. (2012). The psychological effects of meditation: A meta-analysis. Psychological Bulletin, 138(6), 11391171. https://doi.org/10.1037/a0028168

Sedlmeier, P., Loße, C., \& Quasten, L. C. (2018). Psychological effects of meditation for healthy practitioners: An update. Mindfulness, 9(2), 371-387. https://doi.org/10.1007/s12671-017$0780-4$

Shannahoff-Khalsa, D. S. (2004). An introduction to Kundalini Yoga meditation techniques that are specific for the treatment of psychiatric disorders. The Journal of Alternative \& Complementary Medicine, 10(1), 91-101. https://doi.org/10.1089/107555304322849011

Shear, J. (Ed.). (2006). The experience of meditation: Experts introduce the major systems. Paragon House.

Sivananda, S. (1975). Concentration and meditation. Divine Life Society Shivanandanagar, India.

Tang, R., \& Braver, T. S. (2020). Predicting individual preferences in mindfulness techniques using personality traits. Frontiers in Psychology, 11, Article 1163. https://doi.org/10.3389/fpsyg.2020.01163 
Tang, Y.-Y., Hölzel, B. K., \& Posner, M. I. (2015). The neuroscience of mindfulness meditation. Nature Reviews Neuroscience, 16(4), 213-225. https://doi.org/10.3389/10.1038/nrn3916

Travis, F., \& Shear, J. (2010). Focused attention, open monitoring and automatic self-transcending: Categories to organize meditations from Vedic, Buddhist and Chinese traditions. Consciousness and Cognition, 19(4), 1110-1118. https://doi.org/10.1016/j.con$\operatorname{cog} .2010 .01 .007$

Van Dam, N. T., van Vugt, M. K., Vago, D. R., Schmalzl, L., Saron, C. D., Olendzki, A., Meissner, T., Lazar, S. W., Kerr, C. E., \& Gorchov, J. (2018). Mind the hype: A critical evaluation and prescriptive agenda for research on mindfulness and meditation. Perspectives on Psychological Science, 13(1), 36-61.

van Vugt, M. K., Pollock, J., Johnson, B., Gyatso, K., Norbu, N., Lodroe, T., Gyaltsen, T., Phuntsok, L., Thakchoe, J., Khechok, J., Lobsang, J., Tenzin, L., Gyaltsen, J., Moye, A., \& Fresco, D. M. (2020). Inter-brain synchronization in the practice of Tibetan monastic debate. Mindfulness, 11(5), 1105-1119. https://doi.org/10.1007/s12671-020-01338-1

Varela, F. J., Thompson, E., \& Rosch, E. (2017). The embodied mind: Cognitive science and human experience. MIT Press.

Venkatesh, S., Raju, T. R., Shivani, Y., Tompkins, G., \& Meti, B. L. (1997). A study of structure of phenomenology of consciousness in meditative and non-meditative states. Indian Journal of Physiology and Pharmacology, 41, 149-153.

Vieten, C., Wahbeh, H., Cahn, B. R., MacLean, K., Estrada, M., Mills, P., Murphy, M., Shapiro, S., Radin, D., Josipovic, Z., Presti, D. E., Sapiro, M., Chozen Bays, J., Russell, P., Vago, D., Travis, F., Walsh, R., \& Delorme, A. (2018). Future directions in meditation research: Recommendations for expanding the field of contemplative science. PLoS One, 13(11), Article e0205740. https://doi.org/10.1371/journal.pone.0205740

Wachholtz, A. B., \& Pargament, K. I. (2005). Is spirituality a critical ingredient of meditation? Comparing the effects of spiritual meditation, secular meditation, and relaxation on spiritual, psychological, cardiac, and pain outcomes. Journal of Behavioral Medicine, 28(4), 369-384. https://doi.org/10.1007/s10865-005-9008-5 
Walsh, R., \& Shapiro, S. L. (2006). The meeting of meditative disciplines and Western psychology: A mutually enriching dialogue. American Psychologist, 61(3), 227-239. https://doi.org/10.1037/0003-066X.61.3.227

West, M. A. (2016). The psychology of meditation: Research and practice. Oxford University Press.

Wickham, H. (2016). ggplot2: Elegant graphics for data analysis. Springer. https://ggplot2.tidyverse.org

Wolf, D. B., \& Abell, N. (2003). Examining the effects of meditation techniques on psychosocial functioning. Research on Social Work Practice, 13(1), 27-42. https://doi.org/10.1177/104973102237471 